\title{
Structure-based design of highly selective inhibitors of the CREB binding protein bromodomain
}

\author{
R. Aldrin Denny, ${ }^{* a}$ Andrew C. Flick, ${ }^{b}$ Jotham Coe, ${ }^{b}$ Jonathan Langille, Arindrajit Basak, ${ }^{b}$ Shenping \\ Liu, ${ }^{c}$ Ingrid Stock, ${ }^{d}$ Parag Sahasrabudhe, ${ }^{c}$ Paul Bonin, ${ }^{d}$ Duncan A. Hay, ${ }^{e}$ Paul E. Brennan,,${ }^{e, f}$ Mathew \\ Pletcher ${ }^{g}$ Lyn H. Jones, ${ }^{* a}$ and Eugene L. Piatnitski Chekler*a
}

ABSTRACT: Chemical probes are required for preclinical target validation to interrogate novel biological targets and pathways. Selective inhibitors of the CREB Binding Protein (CREBBP)/EP300 bromodomains are required to facilitate the elucidation of biology associated with these important epigenetic targets. Medicinal chemistry optimization, that paid particular attention to physiochemical properties, delivered chemical probes with desirable potency, selectivity and permeability attributes. An important feature of the optimization process was the successful application of rational structurebased drug design to address bromodomain selectivity issues (particularly against the structurally related BRD4 protein).
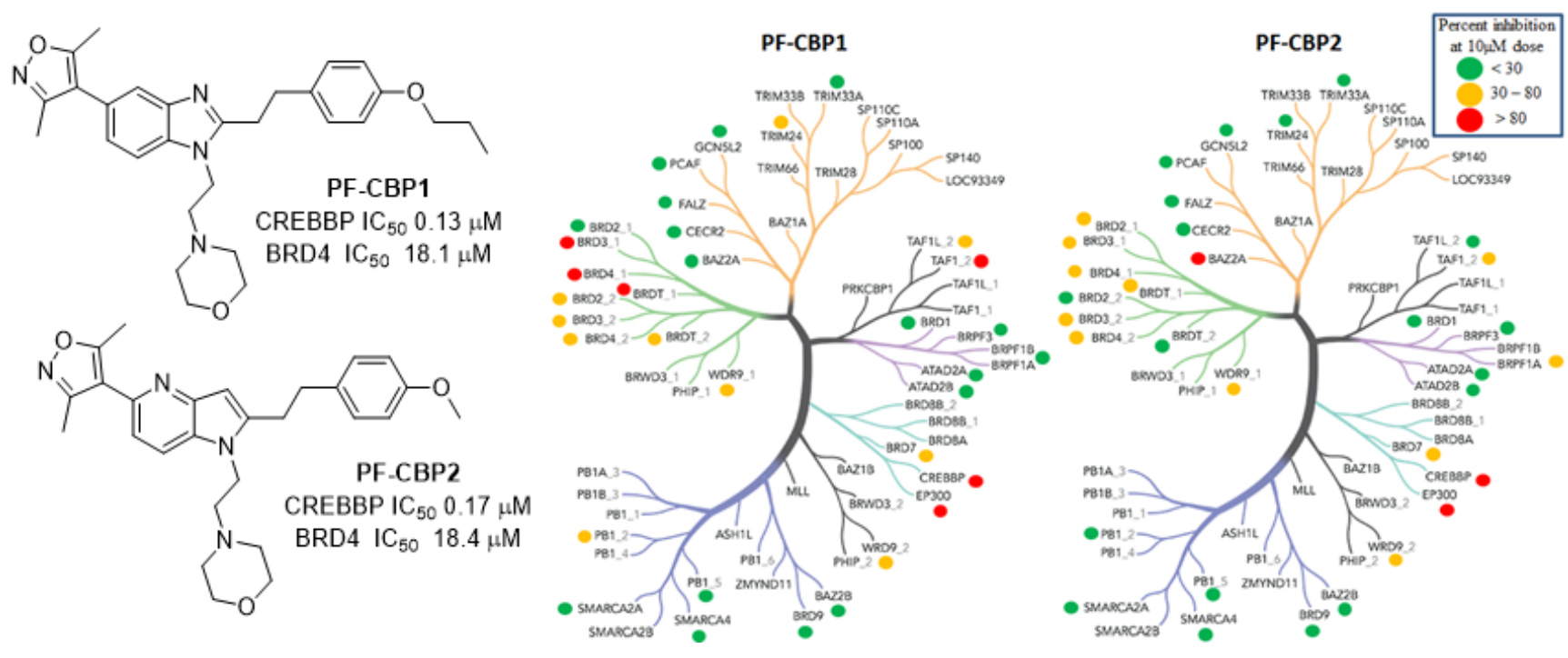


\section{Introduction}

Post-translational modifications of chromatin regulate cellular transcription. The dynamic processes of remodeling histone tails are performed using epigenetic proteins called 'writers', 'readers' and 'erasers'. Epigenetic writers such as histone acetyltransferases, histone methyltransferases, protein arginine methyltransferases and kinases install one or more post-translational marks, including acetyl, methyl and phosphate groups, on the histone tail. Histone deacetylases, lysine demethylases and phosphatases are epigenetic erasers that remove these marks and proteins containing bromodomains, chromodomains and Tudor domains read epigenetic marks to trigger downstream signaling.

Epigenetic aberrations are recognized as key drivers for several human diseases and drug discovery efforts in this area have primarily focused on writer and eraser proteins. ${ }^{1}$ Recently, there has been an increased interest in histone reader proteins for several indications. ${ }^{2}$ Proteins that possess a bromodomain are able to read the acetyl lysine marks associated with epigenetic information transfer. Small molecule inhibitors that perturb acetyl lysine reading interactions are used to decipher their associated biology. ${ }^{1}$ One such example that of BET bromodomain inhibitors, has also illustrated the therapeutic potential of this class. ${ }^{2-3}$

CREB Binding Protein (CREBBP or CBP) is a master transcriptional regulator primarily involved in the activation of gene transcription. It is a ubiquitously expressed target that plays a key role in transcriptional activation in human cells. CREBBP possesses many domains including a nuclear receptor interaction domain, the CREB and MYB interaction domain, the cysteine/histidine region, an interferon response binding domain and a single bromodomain. The bromodomain acetyllysine reader is responsible for the recruitment of the transcription factor, CREB, to its promoter binding sites. CREBBP is also known to interact with many proteins, including p53 to induce the transcription of p53 target genes. BET bromodomain biology has been significantly illuminated through the use of selective chemical probes. ${ }^{4}$ We reasoned that learnings from the medicinal chemistry of BET bromodomains could be applied to the development of selective CREBBP bromodomain inhibitors to further interrogate the biology and therapeutic potential of this target. We recently reported the culmination of our efforts towards this goal that included the development and transcriptional profiling of a selective CREBBP/EP300 inhibitor (PF-CBP1) that highlighted the opportunities for this pharmacological approach in neurodegenerative diseases. ${ }^{5}$ Here we detail our broader medicinal chemistry efforts that have successfully yielded multiple novel and selective lead 
series that should considerably accelerate drug discovery in this area. A significant effort to discover CREBBP selective tools and to study them in various biological systems has been launched by several research groups. ${ }^{6}$ The Structural Genomics Consortium (SGC) team has recently published a 40 -fold selective probe SGC-CBP30 and demonstrated an interesting CREBBP/p53 associated biology (Figure 1). ${ }^{6 c,} 7$ Working concurrently with the SGC team, it became our goal to obtain highly selective molecules to help further elucidate differences in the biology of CREBBP and BET bromodomains.

Achieving selectivity across the bromodomain family is a challenging task, but a recent publication by the SGC demonstrated the possibility of designing CREBBP chemical tools. ${ }^{7}$ The SGC had previously disclosed the isoxazole CREBBP inhibitor $\mathbf{1}$ which was used by our group as a starting point to design novel CREBBP selective probe molecules (Table 1). ${ }^{3 c, 6 c, 7-8}$ The project's objectives were to identify potent CREBBP tool compounds with 100-fold selectivity over other bromodomains, particularly BRD4. Here we report the design of selective CREBBP inhibitors that are structurally distinct from the recently reported compounds GNE272 ${ }^{3 \mathrm{c}}$ and CPI637.3b ${ }^{3 \mathrm{C}}$ The myriad of small molecule-BRD4 crystal structures, and our own work to generate crystal structures with CREBBP, provided confidence that structure-based design could be used to achieve the desired selectivity profile in lead-like series for the project.

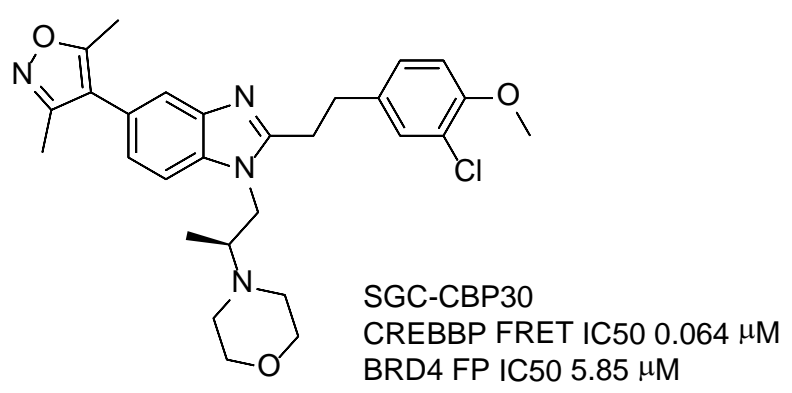

Figure 1. Chemical structure of SGC chemical probe SGC-CBP30.

Bromodomains are comprised of 4 helix bundles that can arrange either in a right or a left handed fashion. ${ }^{9}$ The helices are labeled as Z, A, B and C in going from the $N$ - to $C$ - terminus (Figure $2 A)$. The spatial orientation of these 4 helix bundles selectively recognizes the monoacetylated terminal lysine in histones. The conserved Asn1168 residue in the $\alpha \mathrm{B}$ helix makes a key hydrogen bond interaction with the acetyl lysine. The loops connecting ZA and BC bundles surround the binding site of the acetyl lysine binding pocket. A network of 5 structural water molecules provides 
opportunities for hydrophilic interactions in the deep end of the binding pocket as shown in Figure 2A. The isoxazole headpiece oxygen in $\mathbf{1}$ makes a hydrogen bonding interaction with the Asn1168 amide moiety and the isoxazole nitrogen points towards water A which bridges with the Tyr1125 (Figure 2B). The benzimidazole connected to the isoxazole core acts as a spacer and the phenethyl substitution makes a key cation- $\pi$ interaction with Arg1173. The morpholine substitution on the benzimidazole acts as a solubilizing group and it points towards solvent. A comparison of the Arg1173 orientation in the compound 1 crystal structure and crystal structures of other ligands (PDB IDs 3SVH and 3P1C) ${ }^{10}$ identified a different orientation of this critical binding residue. When CREBBP is crystallized with small ligands that are incapable of making cation- $\pi$ interactions (Figure 3A) the guanidine moiety of Arg1173 points in the North-South orientation and all the carbon atoms of the Arg1173 side chain exist in the low energy staggered orientation. ${ }^{11}$ This is an expected orientation in the apo-protein crystal structure (such as 3DWY). ${ }^{10}$ However, compound $\mathbf{1}$ induces a conformational change to rotate the guanidine in Arg1173 to an East-West orientation, and also introduces a higher energy gauche conformation along the $\mathrm{C} \gamma-\mathrm{C} \delta$ bond as shown in Figure 3B. An additional illustration of CREBBP and BRD4 binding pockets is shown in the supplemental material section (Figure S1 and Table S1). This ligand-induced residue rotation enables the cation- $\pi$ interaction to be made. In addition, a careful investigation of the binding orientation of the phenethyl substituent in compound $\mathbf{1}$ reveals a higher energy gauche orientation along the ethyl bond. This observation emphasizes the importance of capturing an energetically favorable cation- $\pi$ interaction in the design of new ligands that compensates for two unfavorable gauche orientations observed in the protein-ligand complex. The enhancement of this cation- $\pi$ interaction thus constitutes a plausible design strategy to achieve requisite potency and selectivity in novel CREBBP bromodomain inhibitors.
A:
B: 

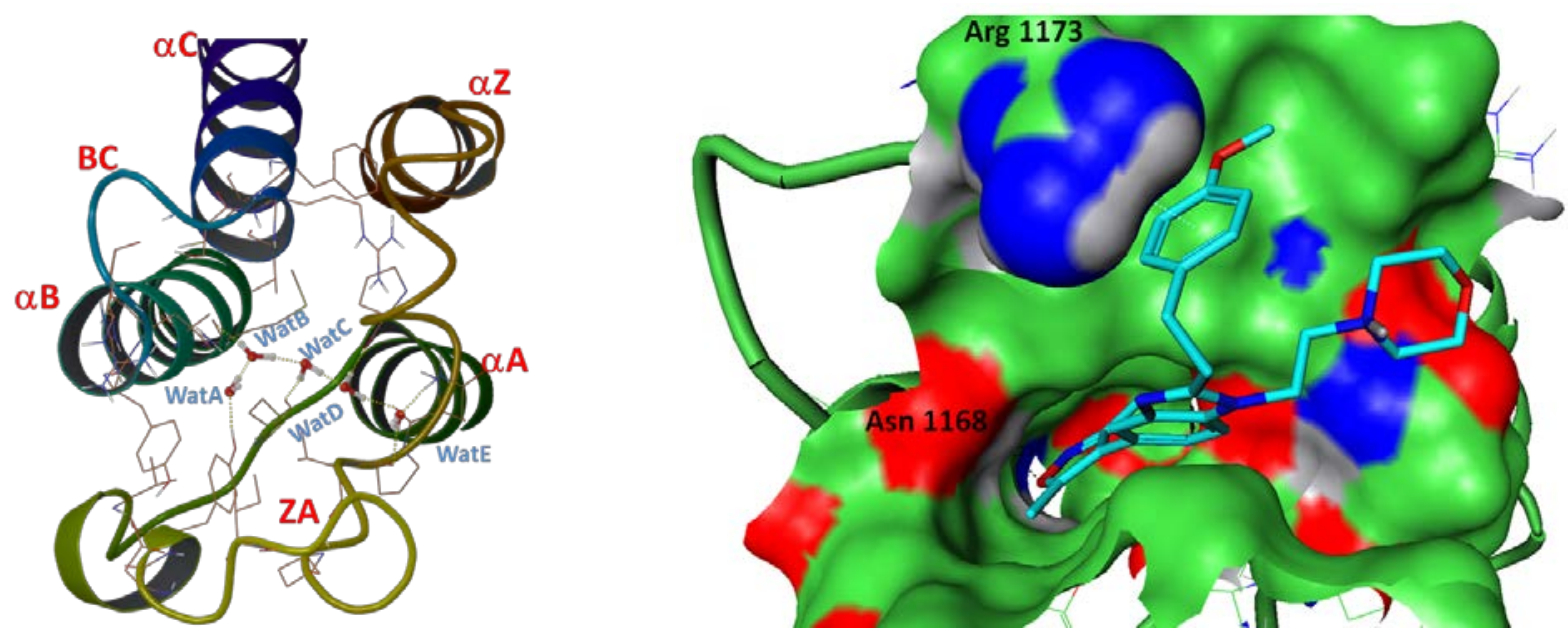

Figure 2. A: CREBBP protein domains with deep pocket water molecules labelled Wat A to E are shown; B: Crystal structure of 1 with CREBBP (PDB Code 5CGP). Cation-pi interaction between the Arg1173 and (4-methyoxy)phenethyl moiety is shown.

(a)

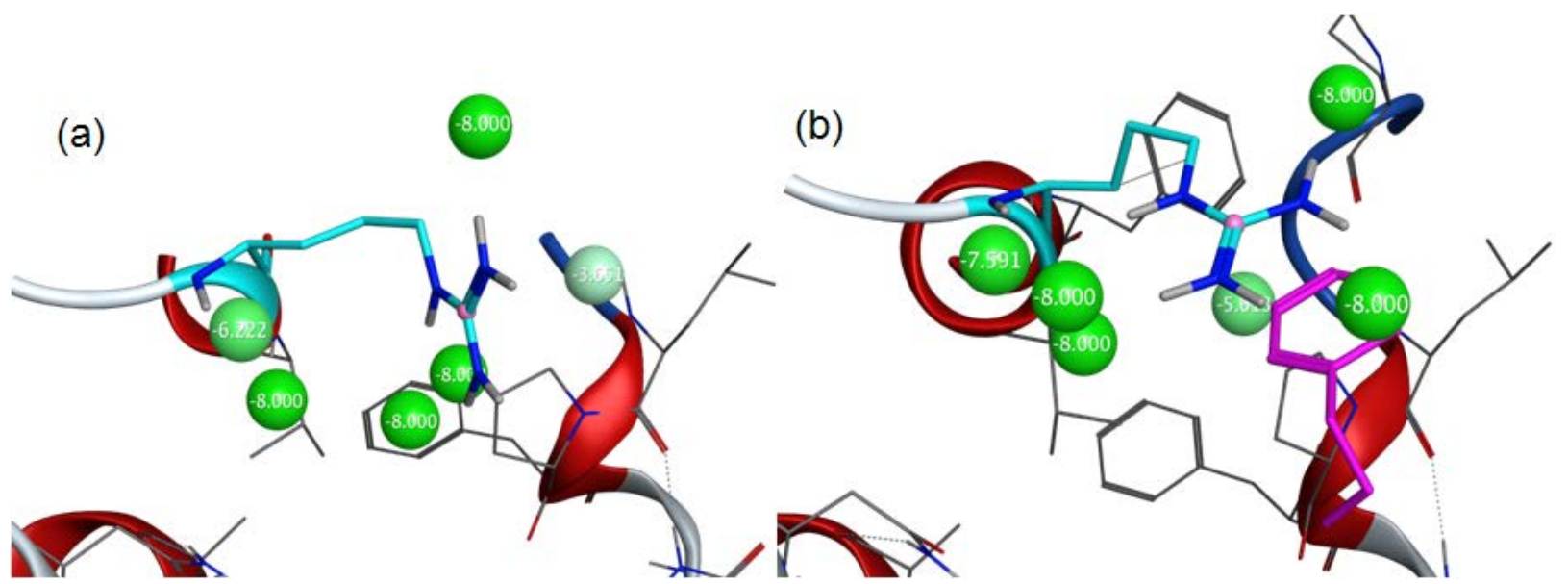

Figure 3. Water molecules around Arg1173 as predicted by 3D RISM. ${ }^{11}$ A: Crystal structure with Arg in the staggered orientation (PDB IDs 3SVH and 3P1C) with predicted bulk water molecules around them (green sphere); B: Arg1173 is in a gauche orientation making an Arg-phenyl interaction. Predicted $\Delta \mathrm{G}$ values for displacing water molecules are depicted on the green sphere.

Electron donating groups on the phenyl ring are expected to enhance cation- $\pi$ interactions according to quantum mechanics calculations. ${ }^{12}$ The unsubstituted phenyl analog 2 is 2-fold less active than the para-substituted compound $\mathbf{1}$ which was first disclosed by the SGC. ${ }^{3 a}$ 6c, 13 A corresponding meta-compound $\mathbf{3}$ turned out to be even less active which is consistent with quantum 
mechanics calculations for cation- $\pi$ interactions. ${ }^{12 \mathrm{~d}}$ However, the ortho-substituted analog 4 showed a significant drop in potency which may indicate an effect of ortho-substitution on the orientation of the phenethyl chain. Ortho- and meta- polar substitution may also lead to undesired solvation effects. Polar substituents on the phenyl ring must interact with the water molecules that solvate the Arg1173 residue. Ortho- and meta-methoxy groups may hinder water molecules from solvating Arg1173, thus creating unfavorable interactions (Figure 3). 3,4-Dimethoxy analog 5 is comparable to $\mathbf{1}$ in terms of lipophilic efficiency $\left(\operatorname{LipE}=\mathrm{pIC}_{50}-\operatorname{LogP}\right)^{14}$ which is a useful parameter in drug design as it describes desirable attributes related to potency and lipophilicity (high quality drug candidates possess a high LipE). 2,4-Dimethoxy compound 6 demonstrated even greater selectivity but with some loss of CREBBP potency. Another approach to enrich electron density within the aromatic system was to install an ether linkage between the benzimidazole and benzene ring, but the corresponding derivatives 7 and 8 lost CREBBP potency either due to a suboptimal tether geometry or the abovementioned solvation effect. The most successful approach to improve selectivity within this scaffold was to expand on the substitution at the para-position. While the hydroxyl-containing derivative $\mathbf{9}$ showed no change in its selectivity profile, ethoxy and propoxy analogs $\mathbf{1 0}$ and $\mathbf{1 1}$ had a remarkable improvement in selectivity (51 and 62-fold respectively). These compounds were followed up in an isothermal titration calorimetry (ITC) assay to confirm their selectivity. Propoxy analog 11 showed no thermal signature in the BRD4 ITC assay which correlates with the weak biochemical BRD4 potency (IC50 18 $\mu \mathrm{M}$, Table S2 in supplemental material section). Compound $\mathbf{1 1}$ (that we named PF-CBP1) was the most selective and potent CREBBP tool compound discovered at that time, and was used as a chemical probe for transcriptional profiling experiments. ${ }^{15}$ Additional para-position modifications 12-20 demonstrated either a loss of CREBBP potency or selectivity. Changing the propoxy group in $\mathbf{1 1}$ to $i$ Pr substituent (12) led to a loss of selectivity, and a similar effect was observed by extending the alkyl chain to butyl (13) or pentyl (14) groups. A remarkable loss in CREBBP potency was observed for the 
electron withdrawing trifluoromethoxy analog 15, while the retention of activity for the nitrilecontaining compound $\mathbf{1 6}$ indicates a more complex picture than a simple cation- $\pi$ interaction paradigm. The loss in potency of $\mathbf{1 5}$ can be attributed to the torsional preference of trifluroanisole, where the trifluoromethoxy moiety orients $90^{\circ}$ from the plane of the phenyl ring ${ }^{16}$ which creates a van der Waals clash with the side chain residues. The influence of an electron donating group on the SAR was further explored with para-amino derivatives 17-19 but the activity and/or selectivity suffered significantly. In the course of the SAR exploration, compound $\mathbf{2 0}$ was found to possess dual CREBBP/BRD4 activity, which served as a useful chemical probe to help delineate differences in inhibiting these bromodomains in our chemical biology studies. ${ }^{5}$ The compounds within this series display acceptable cellular permeability, thus making them suitable for cell-based studies. For example, the passive permeability rate for the chemical probes $\mathbf{1 1}$ and $\mathbf{2 0}$ are $7.9 \times 10^{-6} \mathrm{~cm} / \mathrm{sec}$ and $4.5 \times 10^{-6} \mathrm{~cm} / \mathrm{sec}$ at $2 \mu \mathrm{M}$, respectively. However, the microsomal clearance for the majority of the compounds from the series is relatively high limiting their applications to predominantly in vitro work. Intrinsic clearance in human microsomal assay for compounds $\mathbf{1 1}$ and 20 are $>300 \mu \mathrm{L} / \mathrm{min} / \mathrm{mg}$ and 206 $\mu \mathrm{L} / \mathrm{min} / \mathrm{mg}$ at $1 \mu \mathrm{M}$ dose, respectively. The tool molecule 11 also demonstrated a relatively clean polypharmacology profile determined in a broad CEREP panel where the activity was observed only for the adrenergic A1a receptor (antagonist, $\mathrm{IC}_{50} 0.62 \mu \mathrm{M}$, Supporting Information Table S3) and Ltype calcium channel (antagonist, $\mathrm{IC}_{50} 3.0 \mu \mathrm{M}$ ).

Table 1. Potency and physicochemical data of the 4-(2-(5-(3,5-dimethylisoxazol-4-yl)-2-phenethyl1H-benzo[d]imidazol-1-yl)ethyl)morpholine chemical class. ${ }^{a}$ 


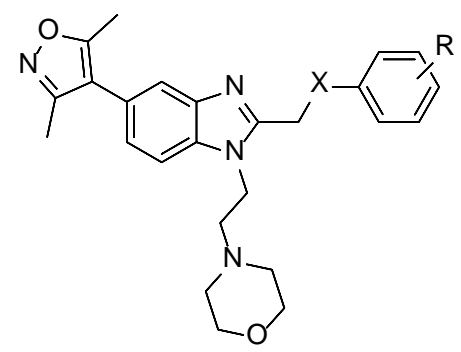

\begin{tabular}{|c|c|c|c|c|c|c|}
\hline Compound & $\mathbf{R}$ & $\mathbf{X}$ & $\begin{array}{l}\text { CREBBP } \\
\text { FRET } \\
\text { IC } 50(\mu \mathrm{M})\end{array}$ & $\begin{array}{l}\text { BRD4 FP } \\
\text { IC } 50(\mu M)\end{array}$ & $\begin{array}{l}\text { CREBBP/BRD } \\
4 \text { fold selectivity }\end{array}$ & $\begin{array}{c}\text { LipE } \\
\text { (CREBBP }^{\text {FRET) }}\end{array}$ \\
\hline 1 & $4-\mathrm{OMe}$ & $\mathrm{CH}_{2}$ & 0.12 & 2.4 & 20 & 3.6 \\
\hline 2 & $\overline{\mathrm{H}}$ & $\mathrm{CH}_{2}$ & 0.24 & 4.1 & 17 & 3.5 \\
\hline 3 & 3-OMe & $\mathrm{CH}_{2}$ & 0.31 & 4.6 & 15 & 2.9 \\
\hline 4 & 2-OMe & $\mathrm{CH}_{2}$ & 0.98 & 13.9 & 14 & 2.2 \\
\hline 5 & $3,4-(\mathrm{OMe})_{2}$ & $\mathrm{CH}_{2}$ & 0.47 & 9.4 & 20 & 3.6 \\
\hline 6 & $2,4-(\mathrm{OMe})_{2}$ & $\mathrm{CH}_{2}$ & 0.24 & 8.3 & 35 & 2.8 \\
\hline 7 & 4-OMe & $\mathrm{O}$ & 0.92 & 9.2 & 10 & 2.8 \\
\hline 8 & $\mathrm{H}$ & $\mathrm{O}$ & 0.40 & 14.4 & 36 & 3.7 \\
\hline 9 & $\mathrm{OH}$ & $\mathrm{CH}_{2}$ & 0.24 & 4.4 & 18 & 3.6 \\
\hline 10 & 4-OEt & $\mathrm{CH}_{2}$ & 0.13 & 6.6 & 51 & 2.8 \\
\hline 11 (PF-CBP1) & 4-OPr & $\mathrm{CH}_{2}$ & 0.13 & 18.1 & 62 & 3.5 \\
\hline 12 & $4-\mathrm{O}-\mathrm{i}-\mathrm{Pr}$ & $\mathrm{CH}_{2}$ & 0.20 & 4.5 & 23 & 2.6 \\
\hline 13 & $4-\mathrm{OBu}$ & $\mathrm{CH}_{2}$ & 0.26 & 11.2 & 43 & 1.9 \\
\hline 14 & 4-O-Pn & $\mathrm{CH}_{2}$ & 0.69 & 6.9 & 10 & 1.5 \\
\hline 15 & $4-\mathrm{OCF}_{3}$ & $\mathrm{CH}_{2}$ & ND & 18.5 & ND & 0.5 \\
\hline 16 & 4-CN & $\mathrm{CH}_{2}$ & 0.30 & 4.9 & 16 & 3.2 \\
\hline 17 & $4-\mathrm{NH}_{2}$ & $\mathrm{CH}_{2}$ & 0.09 & 3.4 & 38 & 3.5 \\
\hline
\end{tabular}




\begin{tabular}{|c|c|c|c|c|c|c|}
\hline $\mathbf{1 8}$ & 4-NMe & $\mathrm{CH}_{2}$ & 0.21 & 4.3 & 20 & 3.6 \\
\hline $\mathbf{1 9}$ & 4-NHAc & $\mathrm{CH}_{2}$ & 0.20 & 1.4 & 7 & 4.2 \\
\hline $\mathbf{2 0}$ & $\left(\mathrm{CH}_{2}\right)_{3} \mathrm{NMe}_{2}$ & $\mathrm{CH}_{2}$ & 0.65 & 1.5 & 3 & 2.6 \\
\hline
\end{tabular}

aExperimental shake-flask LogD values were used.

One of our strategies to improve CREBBP potency was to establish ligand interactions such as a shielded salt bridge or a hydrogen bond with the Arg145 residue in the CREBBP binding pocket. This residue appeared to be accessible from the phenethyl tail present in the chemotype. Various heterocyclic derivatives were prepared to probe hydrogen bonding interactions with the Arg145 residue. Complicated structure-activity relationships in the phenethyl region of the molecule were further demonstrated by exploring heterocyclic substituents in place of the phenyl ring (Table 2). The 2-fold loss of CREBBP activity in 3-pyridyl analog 22 compared to 2-pyridyl (21) and 4-pyridyl (23) derivatives is consistent with the lone pair of 22 making unfavorable interactions with the water molecule, similar to that seen for meta-substituted derivative 3. Another BRD4/CREBBP selectivity approach was to take advantage of the residue differences between these two bromodomain binding sites (Table S1, supplemental material section). Trp81 in BRD4 (Figure 4A) is significantly larger than the corresponding Leu81 in CREBBP, suggesting that adding appropriate substitution to the ligand template in this region may establish a van der Waals clash. Indolyl compound $\mathbf{2 4}$ was intended to support the hypothesis that electron rich heterocycles may improve CREBBP binding, as well as decrease BRD4 potency by increasing steric bulk, but the secondary binding effects besides the cation$\pi$ interaction, likely played a role in decreasing CREBBP activity, and the drop in BRD4 potency was not significant. Quinolinyl analogs 25 and 26 represent an interesting example of the complexity of the SAR in this region. The CREBBP potency of $\mathbf{2 5}$ is more than 10-fold higher than the regioisomer 26 which cannot be explained by stereoelectronic considerations related to the key cation- $\pi$ interactions. The BRD4 activity of $\mathbf{2 5}$ turned out to be similar to the parent molecule $\mathbf{2}$ thus indicating a significant flexibility of the BRD4 binding pocket around the Trp81 residue. A substitution in this region was further explored by preparing a library of alkyl and aryl derivatives with a direct bond to the benzimidazole core. Compound 27 was discovered as a hit with appreciable CREBBP potency (and impressive LipE) even though CREBBP/BRD4 selectivity did not improve over the phenethyl chemotype. The binding mode of $\mathbf{2 7}$ is not able to adopt a cation- $\pi$ interaction similar to the phenethyl 
derivatives, thus indicating a potentially novel binding mode that would need to be further elucidated using X-ray crystallography.

Table 2. Structure-activity relationships relating to modifications of the phenethyl substituent.

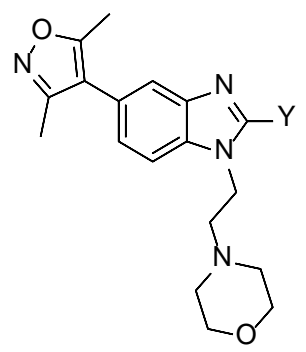

\begin{tabular}{|c|c|c|c|c|c|}
\hline Compound & $\mathbf{Y}$ & $\begin{array}{c}\text { CREBBP } \\
\text { FRET } \\
\text { IC }_{50}(\mu \mathrm{M})\end{array}$ & $\begin{array}{l}\text { BRD4 FP } \\
\text { IC } 50(\mu \mathrm{M})\end{array}$ & $\begin{array}{l}\text { CREBBP } \\
\text { /BRD4 fold } \\
\text { selectivity }\end{array}$ & LipE \\
\hline 21 & $\mathrm{CH}_{2} \mathrm{CH}_{2}$-2-pyridyl & 0.33 & 3.2 & 10 & 4.7 \\
\hline 22 & $\mathrm{CH}_{2} \mathrm{CH}_{2}$-3-pyridyl & 0.78 & 5.8 & 7.4 & 4.3 \\
\hline 23 & $\mathrm{CH}_{2} \mathrm{CH}_{2}-4$-pyridyl & 0.40 & 4.1 & 10 & 4.6 \\
\hline 24 & $\mathrm{CH}_{2} \mathrm{CH}_{2}$-3-indolyl & 0.74 & 10.1 & 14 & 2.9 \\
\hline 25 & $\begin{array}{l}\mathrm{CH}_{2} \mathrm{CH}_{2}-2- \\
\text { quinolinyl }\end{array}$ & 0.16 & 4.9 & 31 & 3.3 \\
\hline 26 & $\begin{array}{r}\mathrm{CH}_{2} \mathrm{CH}_{2}-4- \\
\text { isoquinolinyl }\end{array}$ & 2.5 & 16.8 & 7 & 2.7 \\
\hline 27 & & 0.13 & 1.6 & 12 & 5.3 \\
\hline
\end{tabular}


A:

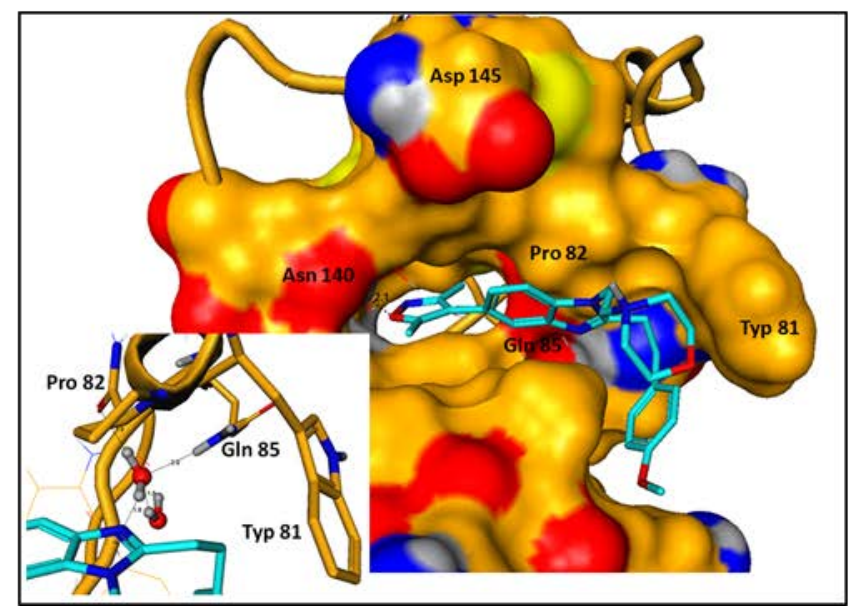

B:

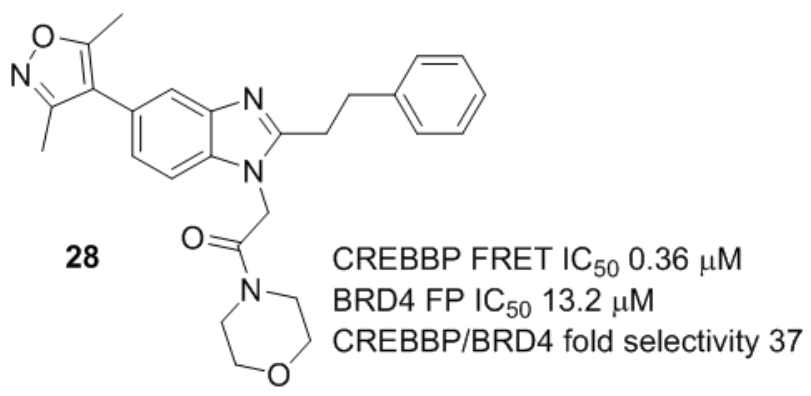

Figure 4. A: Crystal structure of 1 with BRD4 (PDB Code 5CFW). B: Compound 28;

Crystal structure of $\mathbf{1}$ determined that the morpholine group points towards the Trp81 region of the BRD4 binding pocket (Figure 4A). Although the keto group of 28 (Figure 4B) decreased BRD4 activity, CREBBP potency generally suffered upon changes in this region. However, a single methyl group with the right stereochemistry in the SGC probe SGC-CBP30 apparently provided a better compromise with respect to both target activities. A crystal structure of BRD4 with compound 1 demonstrated that Trp81 of BRD4 is rotated around the $\mathrm{C}_{\text {alpha }}-\mathrm{C}_{\text {beta }}$ bond by about 130 degrees and also $\mathrm{C}_{\text {beta }}$ is shifted by about $1 \AA$ (Figure $4 \mathrm{~A}$ ). This movement and rotation makes the pocket wider, thus providing a hydrophobic enclosure for compounds 1, 2 and their analogs. The phenethyl moiety occupies a small pocket in the BRD4 active site and the morpholine group points straight out towards solvent. It is important to note that this orientation is a different binding mode compared to the CREBBP binding pose shown in Figure 2B. This observation provides opportunities for further selectivity enhancements through the development of constrained derivatives (Figure 5). For instance, the selectivity was improved to 67-fold for compound 29. Conformational constraints in the ethyl tether were further explored (Figure 6). According to the dihedral computation, it was proposed that the 5- and 6-membered ring systems are predicted to have less strain than other ring sizes, and are closer to the crystal structure dihedral angle as shown in Figure 6. The remarkable drop in selectivity for compound $\mathbf{3 0}$ supports the hypothesis that a specific orientation is crucial to retain binding potency and selectivity. Further exploration of this strategy to provide $\mathbf{3 1}$ and $\mathbf{3 2}$ led to a loss of CREBBP potency likely due to the change in orientation of the morpholine ring. 
29

CREBBP FRET IC $50.14 \mu \mathrm{M}$

BRD4 FP IC $509.4 \mu \mathrm{M}$

CREBBP/BRD4 fold selectivity 67<smiles>Cc1noc(C)c1-c1ccc2[nH]c([C@@H]3CCO[C@H]3c3ccccc3)nc2c1</smiles>

31

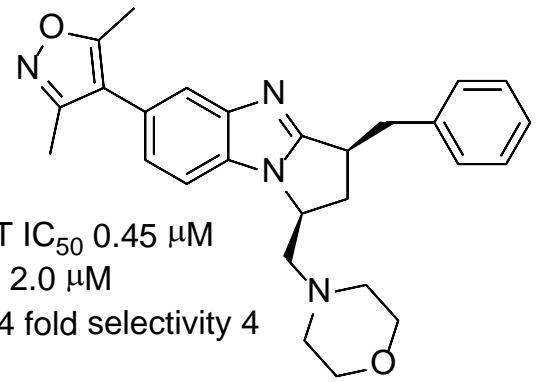

30

CREBBP FRET IC $500.076 \mu \mathrm{M}$

BRD4 FP IC $500.49 \mu \mathrm{M}$

CREBBP/BRD4 fold selectivity 6

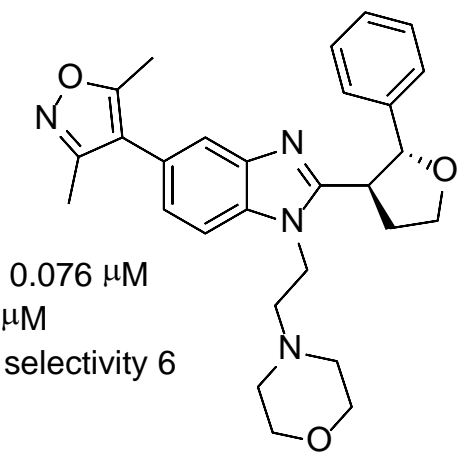

32

CREBBP FRET IC $501.3 \mu \mathrm{M}$

BRD4 FP IC ${ }_{50}>80 \mu \mathrm{M}$

CREBBP/BRD4 fold selectivity $>62$

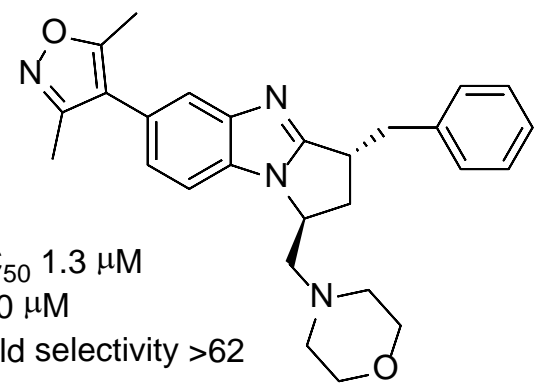

Figure 5. Constrained analogs at both morpholine and phenethyl chains (absolute stereochemistry arbitrarily assigned).

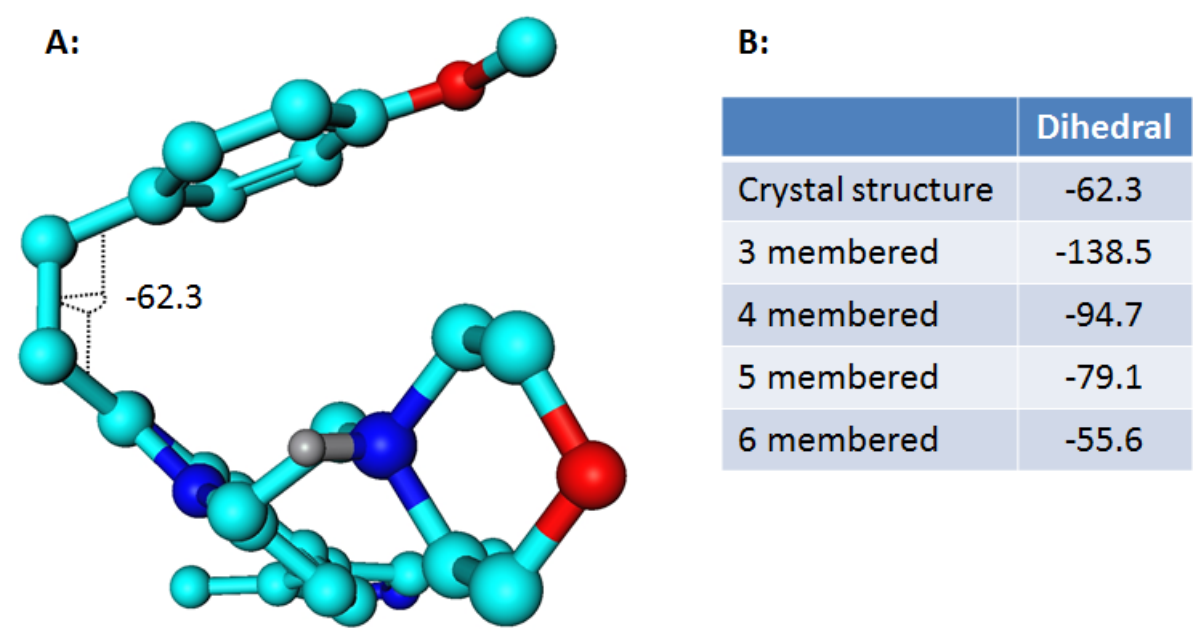

Figure 6. A: The dihedral angle of 1; B: The dihedral angle table for the lowest energy conformation in the crystal structure of $\mathbf{1}$ and cyclization to provide the 3- to 6-membered ring systems at the phenethyl group. 


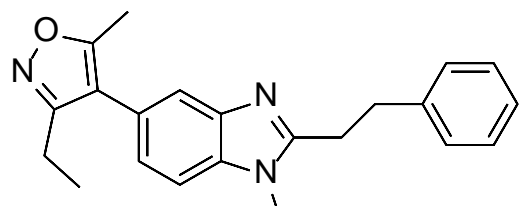

33

CREBBP FRET IC $500.31 \mu \mathrm{M}$ BRD4 FP IC $\mathrm{IC}_{50} 6.0 \mu \mathrm{M}$
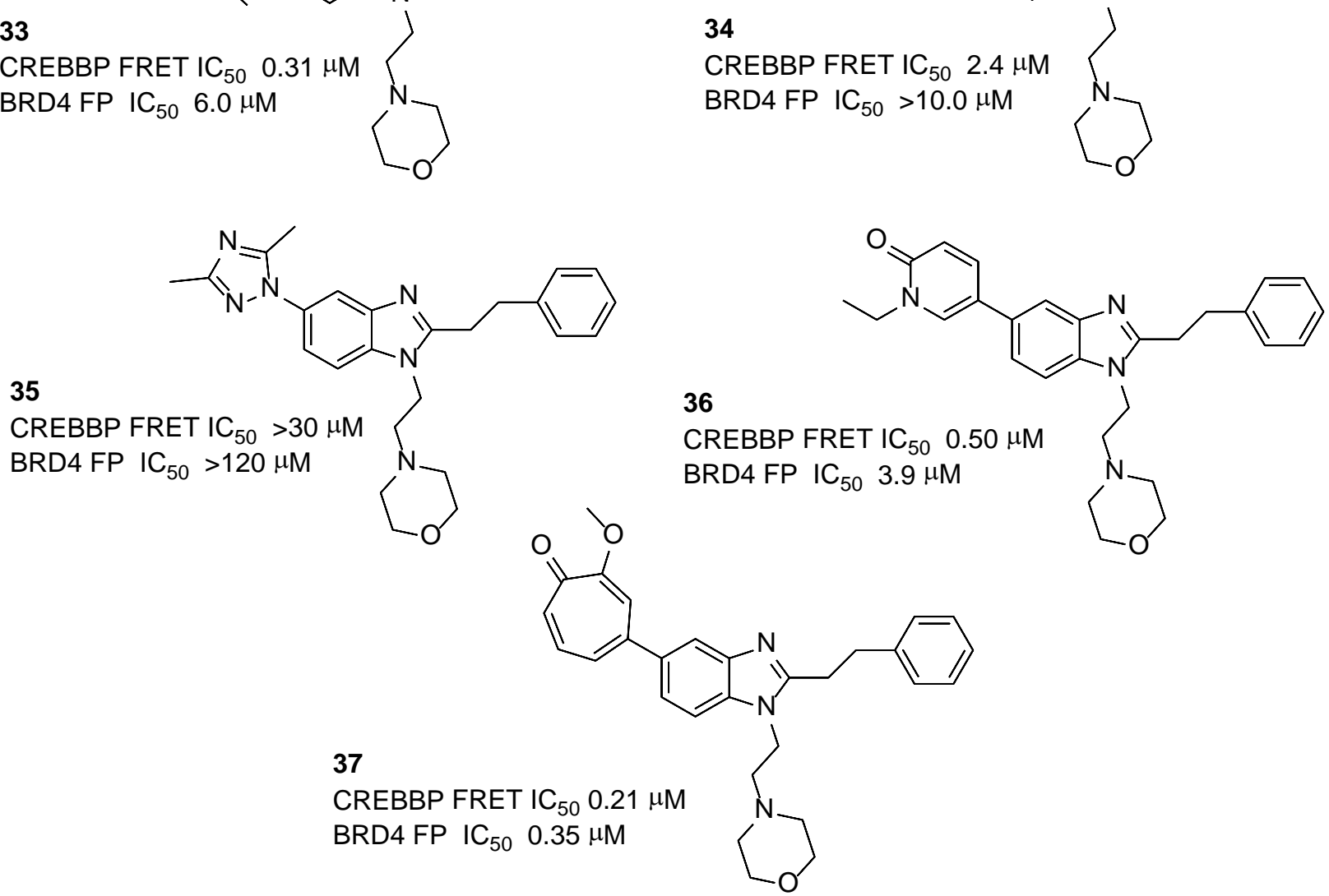

Figure 7. Modifications to the acetyl lysine mimic headpiece.

The dimethylisoxazole head group is a common acetyl lysine mimic used in various bromodomain inhibitors, ${ }^{13,17}$ and it became our goal to replace this fragment with alternative head pieces. Pyrazole derivative $\mathbf{3 4}$ demonstrated that one of the hydrogen bond acceptors of the isoxazole ring cannot be substituted with a hydrogen bond donor to reverse an interaction with water A (Figure 7). Compound 35 suggested that a single hydrogen bond acceptor atom is also not sufficient for potent binding to either BRD4 or CREBBP. $N$-ethylpyridone analog 36 and tropolone derivative 37 were prepared as part of a library with various heterocyclic moieties. These compounds prove that the dimethylisoxazole group can be substituted with alternative head pieces though with some loss of potency. We have previously described the utility of tropolone bromodomain inhibitors from this work as photoaffinity probes of cell-based target occupancy. ${ }^{6 a}$ 
An additional structure-based drug design strategy to improve selectivity was to restrict the inhibitors into their desired conformation by forming an atropisomer. To determine whether a compound would exist as an atropisomer we performed a dihedral scan using molecular mechanics and quantum mechanics calculations. A systematic dihedral scan of the rotatable bond was performed in MacroModel $^{18}$ using OPLS 2005 force field and energy barriers were calculated. If the energy barrier for the dihedrals were found to be $<15 \mathrm{kcal} / \mathrm{mol}$, the compound was classified as not being atropisomeric and no further QM calculations were performed. If the energy barrier is calculated to be above $15 \mathrm{kcal} / \mathrm{mol}$, additional dihedral scans were performed using quantum mechanics using Terachem Program from Petachem LLC. ${ }^{19}$

Quantum mechanics dihedral scans were performed at the B3LYP/6-31G level of theory. Torsional scan around the bond were performed using a rotational step of 30 degrees. After each rotation, the resulting structure was optimized using a relaxed termination criterion with Etolerance of $5 \mathrm{x}$ $10^{-4}$ hartree. During optimization, coordinates of the four atoms that define the given dihedral angle were kept fixed and all other atoms were allowed to move. On the optimized structures, single point energies were calculated. If the barrier height based on single point energies was calculated to be $>20$ $\mathrm{kcal} / \mathrm{mol}$ then the compound was classified as very likely to exhibit atropisomerism. The torsional profile scan using molecular mechanics and QM calculations showed an energy barrier of 24.2 and $22.8 \mathrm{kcal} / \mathrm{mol}$ respectively for the rotation around the isoxazole/benzimidazole bond by adding methyl substituents to positions 4 and 6 of the benzimidazole 38 (ISOX-INACT, Figure 8). ${ }^{5}$ This atropisomer rigidifies the benzimidazole ring at $90^{\circ}$ from the isooxazole ring there by clashing with Trp81 in BRD4 in both its orientations. This negative interaction with Trp81 explains the reduced potency of binding to BRD4 $\left(\mathrm{IC}_{50}>120 \mu \mathrm{M}\right)$ as expected. The loss of CREBBP potency was significant due to poor conserved interactions with the Asn1168 residue and cation- $\pi$ interactions with the Arg1173 residue. This compound in fact served as a useful negative control for this chemotype in our previously described cell-based experiments. ${ }^{5}$

Finally, a successful selectivity approach was discovered by converting the benzimidazole core into an indole moiety (Figure 8). The benzoimide N-3 nitrogen, as seen in the BRD4 crystal structure acts as a hydrogen bond acceptor to Water E, thus mediating an interaction with Pro82 (Figure 4B). Our strategy was to convert the benzimidazole into an indole group therefore preventing the hydrogen bonding interaction. Indole analog 39 showed a significant decrease in BRD4 potency. However, the 
CREBBP binding mode would cause there to be an unfavorable orientation of the indole position 3 hydrogen towards the solvent exposed region of the pocket. Therefore, a more polar substituent might be favored in this area of the molecule and cyano group in $\mathbf{4 0}$ was expected to be pointing to the solvent exposed region in CREBBP. Incorporation of a nitrile moiety to yield derivative $\mathbf{4 0}$ resulted in a complete loss of BRD4 activity i.e., greater than 240-fold selectivity, with CREBBP potency remaining within several fold of compound $\mathbf{1}$ activity. To accommodate a more polar substitution in this area of the indole chemotype, we converted indole analog 39 into Azoindole 41 where the additional nitrogen atom would be pointing towards solvent. Azaindole $\mathbf{4 1}$ showed an improvement in CREBBP potency to a level comparable to compound 1 activity (170 nM). BRD4 potency remained weak (18.4 $\mathrm{uM})$ resulting in >100-fold selectivity in the biochemical assays. Lead molecule $\mathbf{4 1}$ also possessed a clean polypharmacology profile $\left(\mathrm{IC}_{50}>5 \mu \mathrm{M}\right.$ in a broad CEREP panel, Supporting Information Table S3), good cellular permeability $\left(6.8 \times 10^{-6} \mathrm{~cm} / \mathrm{sec}\right.$ at $\left.2 \mu \mathrm{M}\right)$, and shake flask LogD (3.29 at $\mathrm{pH}$ 7.4). The discovery of this very selective and potent chemotype using structure-based design provides confidence in the future medicinal chemistry development of this series.
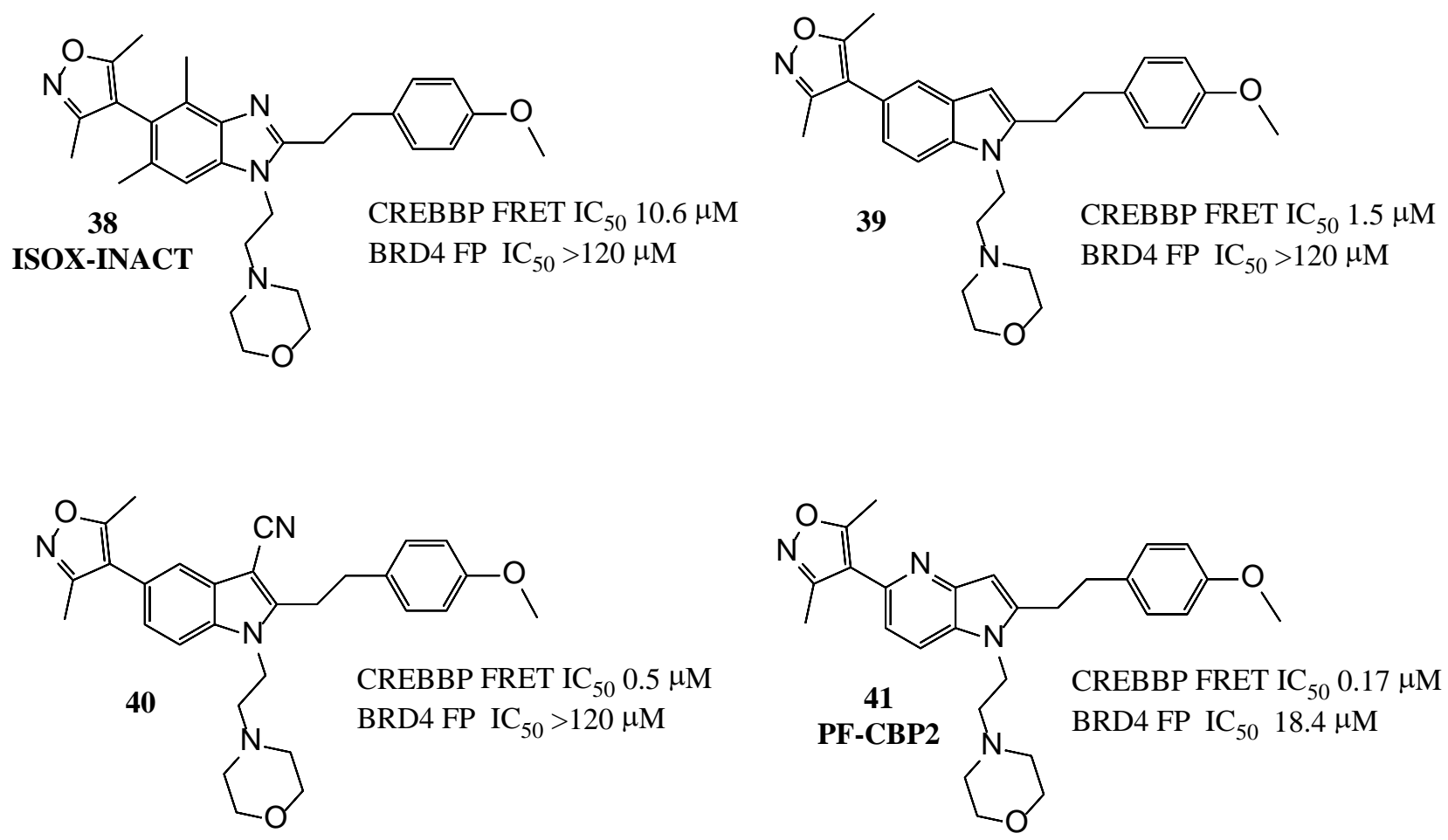

Figure 8. Benzimidazole core modifications

The bromodomain selectivity of lead compounds was assessed using the DiscoveRx BROMOScan platform. ${ }^{15}$ A screening panel of more than 30 bromodomains was utilized. The ultra- 
sensitive qPCR based technology demonstrated a correlation with internally generated data. Even though the assay formats of BROMOScan and biochemical/biophysical assays may account for the differences in potency values, general trends support the selectivity of the isoxazole-benzimidazole compound class (Figure 9). Both compounds 11 and $\mathbf{4 1}$ demonstrated activity for the closely related target EP300 that possesses significant homology to CREBBP with respect to the bromodomain binding pocket. It is interesting to note that the bromodomain selectivity profile of compound $\mathbf{4 1}$ surpasses that of compound 11, thus suggesting $\mathbf{4 1}$ would serve as a useful lead series for future drug discovery efforts.
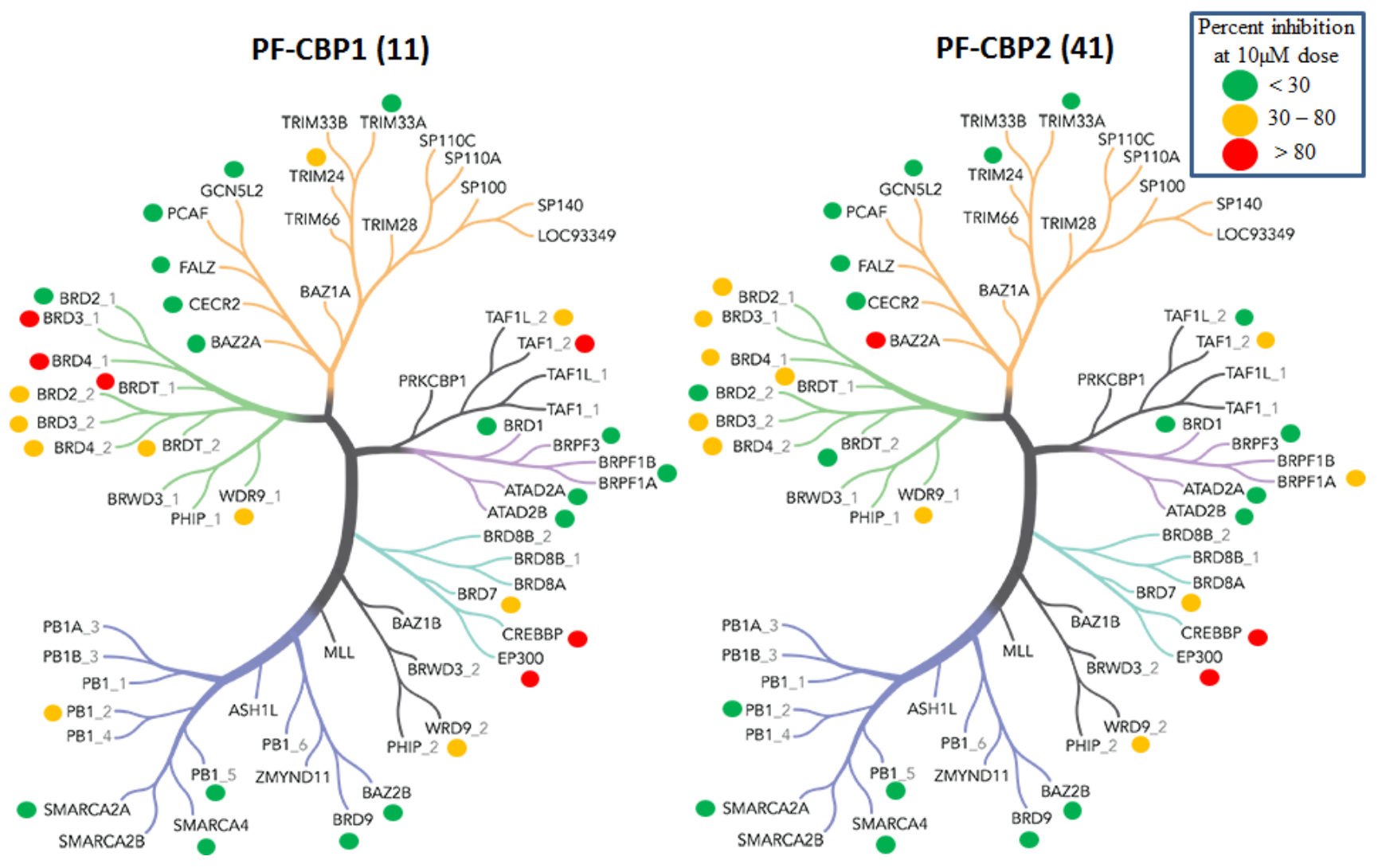

Figure 9. Bromodomain selectivity profile of lead molecules PF-CBP1 (11) and PF-CBP2 (41). Green, yellow and red dots indicate the inhibition $<30 \%, 30-80 \%$ and $>80 \%$ respectively in the DiscoveRX assay at $10 \mu \mathrm{M}$ dose.

In conclusion, we have developed highly selective inhibitors of the CREBBP/EP300 bromodomains using structure-based drug design. These compounds will serve as useful lead series for future drug discovery efforts that should focus on addressing other important features such as metabolic stability. Through this work we identified chemical probes PF-CBP1 and PF-CBP2 that have 
found utility in cell biology and transcriptional profiling experiments that furthers our understanding of CREBBP bromodomain pharmacology. ${ }^{5}$ Novel acetyl lysine mimics were also identified that should be of broad interest to those working in this area.

\section{Experimental Section}

\section{Synthesis}

Starting materials and other reagents were purchased from commercial suppliers and were used without further purification unless otherwise indicated. All reactions were performed under a positive pressure of nitrogen, argon, or with a drying tube, at ambient temperature (unless otherwise stated), in anhydrous solvents, unless otherwise indicated. Analytical thin-layer chromatography was performed on glass-backed Silica Gel 60_F 254 plates (Analtech $(0.25 \mathrm{~mm})$ ) and eluted with the appropriate solvent ratios $(\mathrm{v} / \mathrm{v})$. The reactions were assayed by high-performance liquid chromatography (HPLC) or thin-layer chromatography (TLC) and terminated as judged by the consumption of starting material. The TLC plates were visualized by UV, phosphomolybdic acid stain, or iodine stain. Microwave assisted reactions were run in a Biotage Initiator. 1H NMR spectra were recorded on a Bruker instrument operating at $400 \mathrm{MHz}$ unless otherwise indicated. 1H NMR spectra are obtained as DMSO$d 6$ or $\mathrm{CDCl} 3$ solutions as indicated (reported in ppm), using chloroform as the reference standard (7.25 ppm) or DMSO-d6 (2.50 ppm). Other NMR solvents were used as needed. When peak multiplicities are reported, the following abbreviations are used: $\mathrm{s}=$ singlet, $\mathrm{d}=$ doublet, $\mathrm{t}=$ triplet, $\mathrm{m}=$ multiplet, $\mathrm{br}$ = broadened, $\mathrm{dd}=$ doublet of doublets, $\mathrm{dt}=$ doublet of triplets. Coupling constants, when given, are reported in Hertz. The mass spectra were obtained using liquid chromatography mass spectrometry (LC-MS) on an Agilent instrument using atmospheric pressure chemical ionization (APCI) or electrospray ionization (ESI). High resolution mass measurements were carried out on an Agilent TOF 6200 series with ESI. All test compounds showed $>95 \%$ purity as determined by either combustion analysis, high-performance liquid chromatography (HPLC), liquid chromatography/mass spectrometry analysis (LCMS), or ${ }^{1} \mathrm{HNMR}$ integration. HPLC conditions were as follows: XBridge C18 column @ $80{ }^{\circ} \mathrm{C}, 4.6 \mathrm{~mm} \times 150 \mathrm{~mm}, 5 \mu \mathrm{m}, 5 \%-95 \% \mathrm{MeOH} / \mathrm{H} 2 \mathrm{O}$ buffered with $0.2 \%$ formic acid/0.4\%

ammonium formate, $3 \mathrm{~min}$ run, flow rate $1.2 \mathrm{~mL} / \mathrm{min}$, UV detection $(\lambda=254,224 \mathrm{~nm})$. Combustion analyses were performed by Atlantic Microlab, Inc. (Norcross, Georgia).

\section{General Approach to substituted benzimidazoles:}



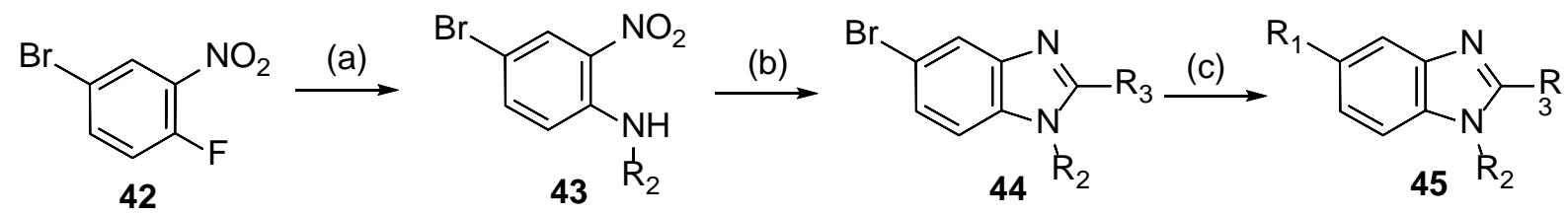

(a) $\mathrm{R}_{2} \mathrm{NH}_{2}, \mathrm{Et}_{3} \mathrm{~N}$, DMSO, $80^{\circ} \mathrm{C}, 18 \mathrm{~h}$; (b) $\mathrm{R}_{3} \mathrm{CHO}, \mathrm{Na}_{2} \mathrm{~S}_{2} \mathrm{O}_{4}, 4: 1 \mathrm{EtOH} / \mathrm{H}_{2} \mathrm{O}, 70{ }^{\circ} \mathrm{C}, 18 \mathrm{~h}$; (c) $\mathrm{R}_{1} \mathrm{~B}(\mathrm{OH})_{2}, \mathrm{PdCl}_{2}$ (dppf) $\mathrm{CH}_{2} \mathrm{Cl}_{2}, \mathrm{Cs}_{2} \mathrm{CO}_{3}, p$-diox. $100^{\circ} \mathrm{C}, 18 \mathrm{~h}$;

\section{General procedure A (Benzimidazole formation):}

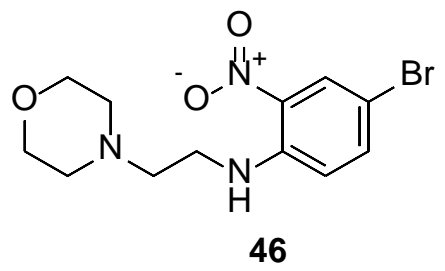

4-Bromo-N-(2-morpholinoethyl)-2-nitroaniline (46): A mixture of 5-bromo-2-fluoronitrobenzene (42) (81.4 g, $0.37 \mathrm{~mol}), N$-(2-aminoethyl)morpholine $(60.0 \mathrm{~g}, 0.46 \mathrm{~mol})$ and triethylamine $(46.5 \mathrm{~g}, 0.46$ mol) in DMSO (1.2 L) was heated to $80^{\circ} \mathrm{C}$ and stirred for 2 hours, when TLC (petroleum ether/EtOAc $=1: 1)$ showed the reaction was complete. To the cooled reaction was added water $(500 \mathrm{~mL})$ and the mixture was extracted with ethyl acetate $(500 \mathrm{~mL} \times 4)$. The combined organic layer was washed with water $(500 \mathrm{~mL})$ and brine $(500 \mathrm{~mL} \times 2)$, dried over $\mathrm{Na}_{2} \mathrm{SO}_{4}$, filtered, and concentrated in vacuo. The residue was purified by flash chromatography (0-50\% ethyl acetate in petroleum ether) to afford the titled 4-Bromo- $\mathrm{N}$-(2-morpholinoethyl)-2-nitroaniline (43) (145 g, 95\%) as an orange solid. ${ }^{1} \mathrm{H}$ NMR (400 MHz, $\left.\mathrm{CDCl}_{3}\right): \delta 2.46-2.58(\mathrm{~m}, 4 \mathrm{H}), 2.69-2.76(\mathrm{~m}, 2 \mathrm{H}), 3.30-3.38(\mathrm{~m}, 2 \mathrm{H}), 3.71-3.80(\mathrm{~m}, 4 \mathrm{H})$, $6.73(\mathrm{~d}, J=9.0 \mathrm{~Hz}, 1 \mathrm{H}), 7.50$ (dd, $J=9.0,1.6 \mathrm{~Hz}, 1 \mathrm{H}), 8.33$ (d, $J=2.4 \mathrm{~Hz}, 1 \mathrm{H}), 8.51$ (br s, 1H); LCMS $m / z 330(\mathrm{M}+1)^{+}$.

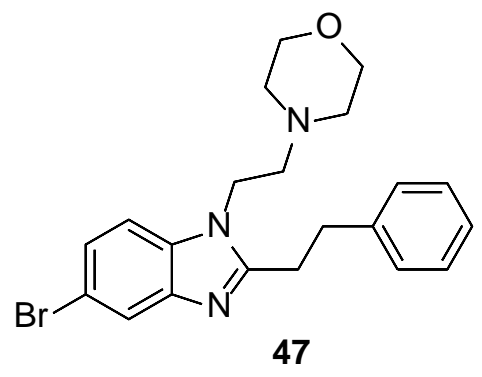

4-(2-(5-bromo-2-phenethyl-1H-benzo[d] imidazol-1-yl)ethyl)morpholine (47): To a mixture of 4Bromo- $N$-(2-morpholinoethyl)-2-nitroaniline (46) (2.01 g, $6.09 \mathrm{mmol})$ and 3-phenylpropionaldehyde (2.50 g, $19.0 \mathrm{mmol})$ in 4:1 ethanol/ $\mathrm{H}_{2} \mathrm{O}(60 \mathrm{~mL}, 0.10 \mathrm{M})$ was added $\mathrm{Na}_{2} \mathrm{~S}_{2} \mathrm{O}_{4}(3.95 \mathrm{~g}, 19.0 \mathrm{mmol})$. The mixture was stirred at $70{ }^{\circ} \mathrm{C}$ for 18 hours under nitrogen. The resulting mixture was diluted with saturated sodium bicarbonate $(50 \mathrm{~mL})$ and extracted with ethyl acetate $(50 \mathrm{~mL} \times 3)$. The combined organic layers were washed with brine $(50 \mathrm{~mL})$, dried over $\mathrm{Na}_{2} \mathrm{SO}_{4}$, filtered and concentrated in vacuo. The residue was purified by flash silica chromatography (0-100\% heptane in ethyl acetate) and the major fraction corresponding to the desired product was collected and concentrated to give the titled 4(2-(5-bromo-2-phenethyl-1H-benzo[d]imidazol-1-yl)ethyl)morpholine $(1.41 \mathrm{~g}, 56 \%)$ as a light yellow oil: ${ }^{1} \mathrm{H}$ NMR(400 MHz, $\left.\mathrm{CDCl}_{3}\right) \delta$ 2.40-2.46 (m, 4H), 2.51 (t, J = 7.0 Hz, 2H), 3.16-3.20 (m, 2H), 3.24- 
3.29 (m, 2H), 3.64-3.69 (m, 4H), $4.06(\mathrm{t}, \mathrm{J}=6.6 \mathrm{~Hz}, 2 \mathrm{H}), 7.17-7.24(\mathrm{~m}, 4 \mathrm{H}), 7.26-7.30(\mathrm{~m}, 2 \mathrm{H}), 7.35$ (dd, J = 8.6, $2.0 \mathrm{~Hz}, 1 \mathrm{H}), 7.89$ (d, J=1.6 Hz, 1H).

4-(2-(5-(3,5-dimethylisoxazol-4-yl)-2-phenethyl-1H-benzo[d] imidazol-1-yl)ethyl)morpholine (2). To a RB flask charged with 4-(2-(5-bromo-2-phenethyl-1H-benzo[d]imidazol-1-yl)ethyl)morpholine (47) (506 mg, $1.22 \mathrm{mmol}$ ), was added sequentially (3,5-dimethylisoxazol-4-yl)boronic acid (260 mg, 1.28 mmol), palladium acetate (17 mg, $0.08 \mathrm{mmol}$ ), RuPHOS (CAS 787618-22-8; $73 \mathrm{mg}, 0.15 \mathrm{mmol}$ ), sodium carbonate $(262 \mathrm{mg}, 2.47 \mathrm{mmol})$, and ethanol $(6.7 \mathrm{~mL}, 0.18 \mathrm{M})$. The mixture was sparged with argon for 5 mins, then heated to $85^{\circ} \mathrm{C}$ for 1.5 hours under nitrogen. The mixture was then cooled to rt and then filtered through a pad of celite and rinsed with ethanol. The filtrates were then concentrated and then purified by flash silica chromatography (0-100\% heptane in ethyl acetate) and the major fraction corresponding to the desired product was collected and concentrated to give the titled compound 2 (333 mg, 63\%) as a viscous yellow oil: ${ }^{1} \mathrm{H}$ NMR(400 MHz, $\left.\mathrm{CDCl}_{3}\right) \delta 2.30$ (s, 3H), 2.43 (s, 3H), 2.45-2.61 (m, 6H), 3.24-3.35 (m, 4H), 3.63-3.81 (m, 4H), 4.07-4.25 (m, 2H), 7.17 (dd, J= 8.2, $1.2 \mathrm{~Hz}, 1 \mathrm{H}$ ), 7.22-7.26 (m, 3H), 7.29-7.33 (m, 2H), 7.43 (br s, 1H), 7.67 (s, 1H).

The following compounds were prepared according to general procedure A:

5-(3,5-dimethylisoxazol-4-yl)-2-[2-(4-methoxyphenyl)ethyl]-1-(2-morpholin-4-ylethyl)-1H-

benzimidazole (1): (1.3 g, 60\%) as yellow liquid. ${ }^{1} \mathrm{H}$ NMR (400 MHz, $\left.\mathrm{CDCl}_{3}\right) \delta 2.30$ (s, 3H), 2.43 (s, $3 \mathrm{H}), 2.44-2.47(\mathrm{~m}, 4 \mathrm{H}), 2.58(\mathrm{t}, J=6.8 \mathrm{~Hz}, 2 \mathrm{H}), 3.15-3.26(\mathrm{~m}, 4 \mathrm{H}), 3.66-3.68(\mathrm{~m}, 4 \mathrm{H}), 3.79(\mathrm{~s}, 3 \mathrm{H})$, $4.11(\mathrm{t}, J=6.8 \mathrm{~Hz}, 2 \mathrm{H}), 6.84(\mathrm{~d}, J=8.0 \mathrm{~Hz}, 2 \mathrm{H}), 7.11-7.16(\mathrm{~m}, 3 \mathrm{H}), 7.34(\mathrm{~d}, J=8.0 \mathrm{~Hz}, 1 \mathrm{H}), 7.63(\mathrm{~d}$, $J=0.8 \mathrm{~Hz}, 1 \mathrm{H})$; LC-MS m/z $461(\mathrm{M}+1)^{+}$.

5-(3,5-Dimethylisoxazol-4-yl)-2-[2-(3-methoxyphenyl)ethyl]-1-(2-morpholin-4-ylethyl)-1Hbenzimidazole (3). Prepared according to general procedure A using 4-(3,5-Dimethylisoxazol-4-yl)- $N$ (2-morpholinoethyl)-2-nitroaniline (100 mg, $0.29 \mathrm{mmol}$ ) and 3-(3-methoxyphenyl)propionaldehyde ${ }^{1}$ giving 3 (10.6 mg, 8\%) as yellow oil. ${ }^{1} \mathrm{H}$ NMR (400 MHz, $\left.\mathrm{CDCl}_{3}\right): \delta 2.29(\mathrm{~s}, 3 \mathrm{H}), 2.42(2,3 \mathrm{H}), 2.44-$ 2.47 (m, 4H), 2.59 (t, $J=6.8 \mathrm{~Hz}, 2 \mathrm{H}), 3.18-3.22(\mathrm{~m}, 2 \mathrm{H}), 3.25-3.30(\mathrm{~m}, 2 \mathrm{H}), 3.66-3.68(\mathrm{~m}, 4 \mathrm{H}), 3.74$ (s, 3H), 4.11 (t, $J=6.8 \mathrm{~Hz}, 2 \mathrm{H}), 6.77-6.79(\mathrm{~m}, 2 \mathrm{H}), 6.84$ (d, $J=7.6 \mathrm{~Hz}, 1 \mathrm{H}), 7.11$ (dd, $J=8.0,1.6 \mathrm{~Hz}$, 1H), 7.21-7.25 (m, 1H), 7.35 (d, $J=8.0 \mathrm{~Hz}, 1 \mathrm{H}), 7.63$ (d, $J=1.2 \mathrm{~Hz}, 1 \mathrm{H})$.

5-(3,5-Dimethylisoxazol-4-yl)-2-[2-(2-methoxyphenyl)ethyl]-1-(2-morpholin-4-ylethyl)-1Hbenzimidazole (4). Prepared according to general procedure A using 4-(3,5-Dimethylisoxazol-4-yl)- $\mathrm{N}$ (2-morpholinoethyl)-2-nitroaniline (125 mg, $0.36 \mathrm{mmol}$ ) and 3-(2'-methoxyphenyl)propionaldehyde ${ }^{2}$ giving 4 (5.3 mg, 4\%) as a brown oil. ${ }^{1} \mathrm{H}$ NMR (400 MHz, $\left.\mathrm{CD}_{3} \mathrm{OD}\right): \delta 2.27$ (s, 3H), $2.43(\mathrm{~s}, 3 \mathrm{H}), 2.47$

${ }^{1}$ Browder, C.C.; Marmsäter, F.P.; West, F.G. Org. Lett., 2001, 3, 3033 DOI: 10.1021/ol010159w.

2 Gangjee, A.; Qiu, Y.; Kisliuk, R.L. J. Heterocyclic Chem. 2004, 41, 941 DOI: 10.1002/jhet.5570410613. 
(t, $J=4.8 \mathrm{~Hz}, 4 \mathrm{H}), 2.63$ (d, $J=6.8 \mathrm{~Hz}, 2 \mathrm{H}), 3.17(\mathrm{~s}, 2 \mathrm{H}), 3.24$ (d, $J=8.0 \mathrm{~Hz}, 2 \mathrm{H}), 3.63$ (t, $J=4.4 \mathrm{~Hz}$, 4H), 3.81 (s, 3H), 4.21 (d, $J=6.4 \mathrm{~Hz}, 2 \mathrm{H}), 6.84$ (d, $J=0.8 \mathrm{~Hz}, 1 \mathrm{H}$ ), 6.97 (d, $J=8.4 \mathrm{~Hz}, 1 \mathrm{H}), 7.08$ (s, $1 \mathrm{H}), 7.22$ (dd, $J=4.0,0.8 \mathrm{~Hz}, 2 \mathrm{H}), 7.54-7.58(\mathrm{~m}, 2 \mathrm{H})$; LC-MS m/z $461(\mathrm{M}+1)^{+}$.

2-[2-(3,4-Dimethoxyphenyl)ethyl]-5-(3,5-dimethylisoxazol-4-yl)-1-(2-morpholin-4-ylethyl)-1Hbenzimidazole (5). Prepared according to general procedure A using 4-(3,5-Dimethylisoxazol-4-yl)- $\mathrm{N}$ (2-morpholinoethyl)-2-nitroaniline (52 $\mathrm{mg}, 0.15 \mathrm{mmol}$ ) and 3-(3,4-dimethoxyphenyl)propionaldehyde ${ }^{3}$ giving 5 (21.2 mg, 29\%) as a brown solid. ${ }^{1} \mathrm{H}$ NMR (400 MHz, $\left.\mathrm{CDCl}_{3}\right): \delta 2.30$ (s, 3H), $2.43(\mathrm{~s}, 3 \mathrm{H})$, 2.45-2.47 (m, 4H), 2.57 (t, $J=6.8 \mathrm{~Hz}, 2 \mathrm{H}), 3.18-3.25(\mathrm{~m}, 4 \mathrm{H}), 3.67-3.69(\mathrm{~m}, 4 \mathrm{H}), 3.72(\mathrm{~s}, 3 \mathrm{H}), 3.86$ (s, 3H), 4.08 (t, $J=6.8 \mathrm{~Hz}, 2 \mathrm{H}), 6.67(\mathrm{~s}, 1 \mathrm{H}), 6.77-6.82(\mathrm{~m}, 2 \mathrm{H}), 7.12$ (d, $J=8.4 \mathrm{~Hz}, 1 \mathrm{H}), 7.34$ (d, $J=$ $8.4 \mathrm{~Hz}, 1 \mathrm{H}), 7.64$ (s, 1H).

2-[2-(2,4-Dimethoxyphenyl)ethyl]-5-(3,5-dimethylisoxazol-4-yl)-1-(2-morpholin-4-ylethyl)-1Hbenzimidazole (6). Prepared according to general procedure A using 4-(3,5-Dimethylisoxazol-4-yl)- $N$ (2-morpholinoethyl)-2-nitroaniline (107 mg, $0.31 \quad \mathrm{mmol})$ and 3-(2',4'dimethoxyphenyl)propionaldehyde ${ }^{4}$ giving $6(6.3 \mathrm{mg}, 5 \%)$ as a brown oil. ${ }^{1} \mathrm{H}$ NMR $(400 \mathrm{MHz}$, $\left.\mathrm{CD}_{3} \mathrm{OD}\right): \delta 2.28(\mathrm{~s}, 3 \mathrm{H}), 2.45(\mathrm{~s}, 3 \mathrm{H}), 3.22(\mathrm{~s}, 4 \mathrm{H}), 3.43(\mathrm{~s}, 6 \mathrm{H}), 3.57(\mathrm{~s}, 4 \mathrm{H}), 3.77(\mathrm{~s}, 4 \mathrm{H}), 4.02(\mathrm{~s}$, 4H), 6.44-6.52 (m, 2H), 7.19 (s, 1H), 7.65-7.73 (m, 2H), 8.20 (s, 1H); LC-MS m/z 491 (M+1).

5-(3,5-Dimethylisoxazol-4-yl)-2-[(4-methoxyphenoxy)methyl]-1-(2-morpholin-4-ylethyl)-1Hbenzimidazole (7). Prepared according to general procedure A using 4-(3,5-Dimethylisoxazol-4-yl)- $\mathrm{N}$ (2-morpholinoethyl)-2-nitroaniline (93 mg, $0.27 \mathrm{mmol}$ ) and (4-methoxyphenoxy)acetaldehyde ${ }^{4}$ giving 7 (9 mg, 7\%) as a colorless solid. ${ }^{1} \mathrm{H}$ NMR $\left(400 \mathrm{MHz}, \mathrm{CD}_{3} \mathrm{OD}\right): \delta 2.27$ (s, 3H), 2.43 (s, 3H), $2.51(\mathrm{~m}$, $4 \mathrm{H}), 2.79-2.83(\mathrm{~m}, 2 \mathrm{H}), 3.64(\mathrm{~m}, 4 \mathrm{H}), 3.75(\mathrm{~s}, 3 \mathrm{H}), 4.53-4.56(\mathrm{~m}, 2 \mathrm{H}), 5.42(\mathrm{~s}, 2 \mathrm{H}), 6.88(\mathrm{~d}, J=8.8$ Hz, 2H), 7.04 (d, $J=8.4 \mathrm{~Hz}, 2 \mathrm{H}), 7.32$ (d, $J=8.0 \mathrm{~Hz}, 1 \mathrm{H}), 7.60$ (s, 1H), 7.69 (d, $J=8.4 \mathrm{~Hz}, 1 \mathrm{H})$; LCMS $m / z 463(\mathrm{M}+1)^{+}$.

5-(3,5-Dimethylisoxazol-4-yl)-2-phenoxymethyl-1-(2-morpholin-4-ylethyl)-1H-benzimidazole

(8). Prepared according to general procedure A using using 4-(3,5-Dimethylisoxazol-4-yl)- $\mathrm{N}$-(2morpholinoethyl)-2-nitroaniline (127 mg, $0.37 \mathrm{mmol}$ ) and phenoxyacetaldehyde giving 8 (9 mg, 6 \%) as a light brown solid. ${ }^{1} \mathrm{H}$ NMR $\left(400 \mathrm{MHz}, \mathrm{CD}_{3} \mathrm{OD}\right): \delta 2.29(\mathrm{~s}, 3 \mathrm{H}), 2.46(\mathrm{~s}, 3 \mathrm{H}), 3.48(\mathrm{~m}, 4 \mathrm{H}), 3.76-$ $3.80(\mathrm{~m}, 2 \mathrm{H}), 4.04(\mathrm{~m}, 4 \mathrm{H}), 5.12-5.15(\mathrm{~m}, 2 \mathrm{H}), 5.83(\mathrm{~s}, 2 \mathrm{H}), 7.11(\mathrm{t}, J=7.5 \mathrm{~Hz}, 1 \mathrm{H}), 7.28-7.30(\mathrm{~m}$, 2H), 7.40-7.44 (m, 2H), 7.66 (d, $J=8.0 \mathrm{~Hz}, 1 \mathrm{H}), 7.80$ (s, 1H), 8.24 (d, $J=8.4 \mathrm{~Hz}, 1 \mathrm{H}$ ); LC-MS $\mathrm{m} / \mathrm{z}$ $433(\mathrm{M}+1)^{+}$.

${ }^{3}$ Ermolae’ev, D.S.; Alifanov, V.L.; Rybakov, V.B.; Babaev, E.V.; Van der Eycken, E.V. Synthesis, 2008, 2083 DOI: 10.1055/s-2008-107844.

${ }^{4}$ Piggott, M.J.; Wege, D. Aust. J. Chem. 2003, 56, 691 DOI: 10.1071/CH02253. 
4-\{2-[5-(3,5-Dimethylisoxazol-4-yl)-1-(2-morpholin-4-ylethyl)-1H-benzimidazol-2-yl]ethyl\}-phenol

(9). A mixture of 4-(2-(5-(3,5-Dimethylisoxazol-4-yl)-2-(4-((tetrahydro-2H-pyran-2yl)oxy)phenethyl)-1H-benzo[d]imidazol-1-yl)ethyl)morpholine (80 $\mathrm{mg}, 0.15 \mathrm{mmol}$ ) in ethanol (1.3 $\mathrm{mL})$ was added concentrated $\mathrm{HCl}(0.76 \mathrm{~mL})$. The mixture was stirred at ambient temperature for 4 hours. The resulting mixture was concentrated in vacuo and purified by prep-TLC to give 9 (55.8 mg, $83 \%)$ as a yellow solid. ${ }^{1} \mathrm{H}$ NMR $\left(400 \mathrm{MHz}, \mathrm{CDCl}_{3}\right): \delta 2.27(\mathrm{~m}, 3 \mathrm{H}), 2.40(\mathrm{~s}, 3 \mathrm{H}), 2.49(\mathrm{~m}, 4 \mathrm{H}), 2.64-$ 2.65 (m, 2H), 3.18 (m, 4H), $3.69(\mathrm{~m}, 4 \mathrm{H}), 4.15$ (m, 2H), 6.73 (d, $J=7.6 \mathrm{~Hz}, 2 \mathrm{H}), 7.01$ (d, $J=8.0 \mathrm{~Hz}$, 2H), 7.12 (d, $J=7.6 \mathrm{~Hz}, 1 \mathrm{H}), 7.36$ (d, $J=7.6 \mathrm{~Hz}, 1 \mathrm{H}), 7.59$ (s, 1H), phenolic proton not observed; LC-MS m/z $447(\mathrm{M}+1)^{+}$.

5-(3,5-Dimethylisoxazol-4-yl)-2-[2-(4-ethoxyphenyl)ethyl]-1-(2-morpholin-4-ylethyl)-1H-

benzimidazole (10). A mixture of 9 (45 $\mathrm{mg}, 0.10 \mathrm{mmol})$ and iodoethane (19 $\mathrm{mg}, 0.12 \mathrm{mmol}$ ) and $\mathrm{K}_{2} \mathrm{CO}_{3}(41 \mathrm{mg}, 0.30 \mathrm{mmol})$ in acetonitrile $\left(2 \mathrm{~mL}\right.$ ) was stirred at $50{ }^{\circ} \mathrm{C}$ for 5 hours. The reaction mixture was filtered and purified by prep-HPLC to give $\mathbf{1 0}(1.6 \mathrm{mg}, 3 \%)$ as a light yellow solid. ${ }^{1} \mathrm{H}$ NMR (400MHz, CDCl $): \delta 1.42$ (t, $J=7.2 \mathrm{~Hz}, 3 \mathrm{H}), 2.31$ (s, 3H), 2.44 (s, 3H), 2.46-2.49 (m, 4H), 2.60 (t, $J=7.2 \mathrm{~Hz}, 2 \mathrm{H}), 3.18-3.24(\mathrm{~m}, 4 \mathrm{H}), 3.67-3.69(\mathrm{~m}, 4 \mathrm{H}), 4.02$ (q, $J=7.2 \mathrm{~Hz}, 2 \mathrm{H}), 4.07-4.13(\mathrm{~m}, 2 \mathrm{H})$, $6.84(\mathrm{~d}, J=8.8 \mathrm{~Hz}, 2 \mathrm{H}), 7.12-7.16(\mathrm{~m}, 3 \mathrm{H}), 7.35$ (d, $J=8.0 \mathrm{~Hz}, 1 \mathrm{H}), 7.64(\mathrm{~s}, 1 \mathrm{H}) ; \mathrm{LC}-\mathrm{MS} \mathrm{m} / \mathrm{z} 475$ $(\mathrm{M}+1)^{+}$.

5-(3,5-Dimethylisoxazol-4-yl)-1-(2-morpholin-4-ylethyl)-2-[2-(4-propoxyphenyl)ethyl]-1H-

benzimidazole (11). A mixture of 9 (45 mg, $0.10 \mathrm{mmol}$ ) and iodopropane (20 $\mathrm{mg}, 0.12 \mathrm{mmol}$ ) and $\mathrm{K}_{2} \mathrm{CO}_{3}(41 \mathrm{mg}, 0.30 \mathrm{mmol})$ in acetonitrile $(2 \mathrm{~mL})$ was stirred at $50{ }^{\circ} \mathrm{C}$ overnight. The reaction mixture was filtered and purified by prep-HPLC to give 11 (4.9 mg, 10\%) as a yellow solid. ${ }^{1} \mathrm{H}$ NMR (400MHz, $\left.\mathrm{CDCl}_{3}\right): \delta 1.04(\mathrm{t}, J=7.6 \mathrm{~Hz}, 3 \mathrm{H}), 1.80-1.83(\mathrm{~m}, 2 \mathrm{H}), 2.31$ (s, 3H), $2.44(\mathrm{~s}, 3 \mathrm{H}), 2.47-2.49$ (m, 4H), 2.58-2.61 (m, 2H), 3.18-3.24 (m, 4H), 3.67-3.69 (m, 4H), $3.91(\mathrm{t}, J=6.8 \mathrm{~Hz}, 2 \mathrm{H}), 4.10-4.13$ (t, $J=7.2 \mathrm{~Hz}, 2 \mathrm{H}), 6.85$ (d, $J=8.8 \mathrm{~Hz}, 2 \mathrm{H}), 7.12-7.15$ (m, 3H), 7.35 (d, $J=8.4 \mathrm{~Hz}, 1 \mathrm{H}), 7.64$ (s, $1 \mathrm{H})$; LC-MS m/z $489(\mathrm{M}+1)^{+}$.

General procedure B (Synthesis of 3-arylpropionaldehydes (49)):

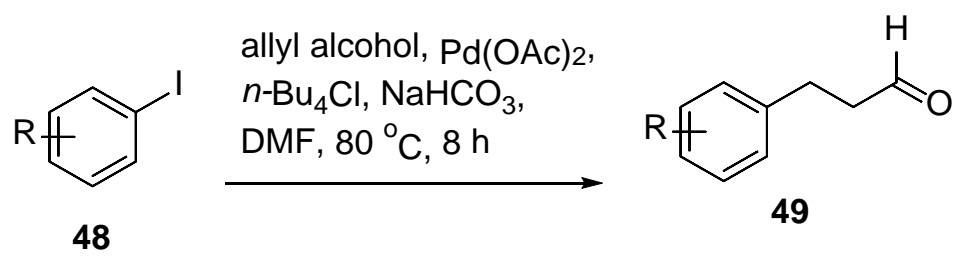

Allyl alcohol (2.0 eq) was added to a solution of the aryl iodide (1.0 eq), $\mathrm{Pd}(\mathrm{OAc})_{2}(0.25 \mathrm{eq}), \mathrm{Bu} 4 \mathrm{NCl}$ (1.33 eq) and $\mathrm{NaHCO}_{3}(3.0 \mathrm{eq})$ in DMF (0.2M). The mixture was allowed to stir at $80{ }^{\circ} \mathrm{C}$ for 8 hours. The mixture was filtered and the resulting filtrate was concentrated in vacuo. The residue was purified by flash chromatography giving the desired 3-arylpropionaldhydes as described below. 


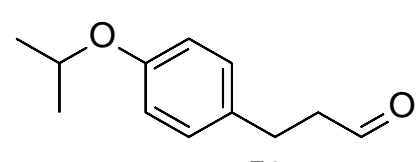

50

3-(4-Isopropoxyphenyl)propionaldehyde (50): Prepared according to general procedure B using 4(isopropoxy)iodobenzene $(200 \mathrm{mg}, 0.76 \mathrm{mmol})$. Purification by flash column chromatography $(5-10 \%$ ethyl acetate in petroleum ether) gave 3-(4-Isopropoxyphenyl)propionaldehyde (55 $\mathrm{mg}, 37 \%$ ) as yellow liquid which exactly matched the previous data provided for this compound. ${ }^{5}$ The material was used directly in the next step.

5-(3,5-Dimethylisoxazol-4-yl)-2-[2-(4-isopropoxyphenyl)ethyl]-1-(2-morpholin-4-ylethyl)-1Hbenzimidazole (12). Prepared according to general procedure A using 4-(3,5-Dimethylisoxazol-4-yl)$\mathrm{N}$-(2-morpholinoethyl)-2-nitroaniline $\quad(468 \quad \mathrm{mg}, \quad 1.35 \quad \mathrm{mmol})$ and 3-(4Isopropoxyphenyl)propionaldehyde giving $12(5 \mathrm{mg}, 4 \%)$ as a yellow solid. ${ }^{1} \mathrm{H}$ NMR $(400 \mathrm{MHz}$, $\left.\mathrm{CDCl}_{3}\right): \delta 1.33(\mathrm{~d}, J=6.0 \mathrm{~Hz}, 6 \mathrm{H}), 2.30(\mathrm{~s}, 3 \mathrm{H}), 2.43(\mathrm{~s}, 3 \mathrm{H}), 2.44-2.48(\mathrm{~m}, 4 \mathrm{H}), 2.58-2.61(\mathrm{~m}, 2 \mathrm{H})$, 3.15-3.25 (m, 4H), 3.65-3.69 (m, 4H), 4.09-4.12 (m, 2H), 4.51 (sept. $J=6.0 \mathrm{~Hz}, 1 \mathrm{H}), 6.83(\mathrm{~d}, J=8.5$ $\mathrm{Hz}, 2 \mathrm{H}), 7.10-7.14$ (m, 3H), 7.35 (d, $J=8.0 \mathrm{~Hz}, 1 \mathrm{H}), 7.63$ (s, 1H); LC-MS m/z 489 (M+1) .

5-(3,5-Dimethylisoxazol-4-yl)-1-(2-morpholin-4-ylethyl)-2-[2-(4-butyloxyphenyl)ethyl]-1Hbenzimidazole (13). To a mixture of $9(0.075 \mathrm{mmol})$ and potassium tert-butoxide $(0.15 \mathrm{mmol})$ in DMA $(0.7 \mathrm{~mL})$ was added iodobutane $(0.11 \mathrm{mmol})$. The mixture was allowed to stir at $60^{\circ} \mathrm{C}$ for 1 hour. The reaction mixture was cooled to room temperature concentrated in vacuo. The residue was purified by prep-HPLC to give 13. LC-MS m/z $502(\mathrm{M}+1)^{+}$.

5-(3,5-Dimethylisoxazol-4-yl)-1-(2-morpholin-4-ylethyl)-2-[2-(4-pentyloxyphenyl)ethyl]-1Hbenzimidazole (14). To a mixture of $9(0.075 \mathrm{mmol})$ and potassium tert-butoxide $(0.15 \mathrm{mmol})$ in DMA $(0.7 \mathrm{~mL})$ was added bromopentane $(0.11 \mathrm{mmol})$. The mixture was allowed to stir at $60{ }^{\circ} \mathrm{C}$ for 1 hour. The reaction mixture was cooled to room temperature concentrated in vacuo. The residue was purified by prep-HPLC to give 14 . LC-MS m/z $517(\mathrm{M}+1)^{+}$.

5-(3,5-Dimethylisoxazol-4-yl)-1-(2-morpholin-4-ylethyl)-2-\{2-[4-(trifluoromethoxy)phenyl]-ethyl\}-1Hbenzimidazole (15). Prepared according to general procedure A using 4-(3,5-Dimethylisoxazol-4-yl)$\mathrm{N}$-(2-morpholinoethyl)-2-nitroaniline $\quad(72 \quad \mathrm{mg}, \quad 0.21 \quad \mathrm{mmol})$ and 3-(4trifluoromethoxyphenyl)propionaldehyde ${ }^{6}$ giving $15(18.2 \mathrm{mg}, 17 \%)$ as yellow oil. ${ }^{1} \mathrm{H}$ NMR $(400 \mathrm{MHz}$,

${ }^{5}$ Khan, A. M. et al PCT2004034999 29 Apr 2004

6 Kim, P.; Kang, S.; Boshoff, H.I.; Jiricek, J.; Collins, M.; Singh, R.; Manjunatha, U.H.; Niyomrattanakit, P.; Zhang, L.; Goodwin, M.; Dick, T.; Keller, T.H.; Dowd, C.S.; Barry, C.E. J. Med. Chem. 2009, 52, 1329 DOI: $10.1021 /$ jm801374t. 
$\left.\mathrm{CDCl}_{3}\right): \delta 2.29(\mathrm{~s}, 3 \mathrm{H}), 2.42(\mathrm{~s}, 3 \mathrm{H}), 2.43-2.46(\mathrm{~m}, 4 \mathrm{H}), 2.60(\mathrm{t}, J=6.8 \mathrm{~Hz}, 2 \mathrm{H}), 3.17-3.20(\mathrm{~m}, 2 \mathrm{H})$, 3.29-3.33 (m, 2H), 3.64-3.66 (m, 4H), 4.12 (t, $J=6.8$ Hz, 2H), 7.11-7.15 (m, 3H), 7.21 (s, $2 \mathrm{H}), 7.34$ (d, $J=8.4 \mathrm{~Hz}, 1 \mathrm{H}), 7.62$ (s, $1 \mathrm{H})$.

4-\{2-[5-(3,5-Dimethylisoxazol-4-yl)-1-(2-morpholin-4-ylethyl)-1H-benzimidazol-2-yl]ethyl\}benzonitrile (16). Prepared according to general procedure A using 4-(3,5-Dimethylisoxazol-4-yl)- $N$ -

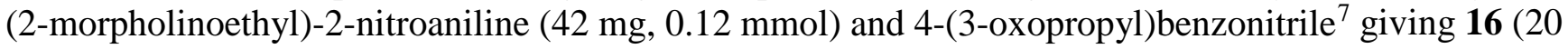
mg, 36\%) as a brown solid. ${ }^{1} \mathrm{H}$ NMR (400MHz, $\left.\mathrm{CDCl}_{3}\right): \delta 2.30(\mathrm{~s}, 3 \mathrm{H}), 2.43(\mathrm{~s}, 3 \mathrm{H}), 2.49(\mathrm{~s}, 4 \mathrm{H}), 2.66$ (t, $J=6.8 \mathrm{~Hz}, 2 \mathrm{H}), 3.22-3.26(\mathrm{~m}, 2 \mathrm{H}), 3.38-3.42(\mathrm{~m}, 2 \mathrm{H}), 3.67-3.69(\mathrm{~m}, 4 \mathrm{H}), 4.18(\mathrm{t}, J=6.8 \mathrm{~Hz}, 2 \mathrm{H})$, $7.15(\mathrm{~d}, J=8.4 \mathrm{~Hz}, 1 \mathrm{H}), 7.37-3.40(\mathrm{~m}, 3 \mathrm{H}), 7.60-7.64(\mathrm{~m}, 3 \mathrm{H})$.

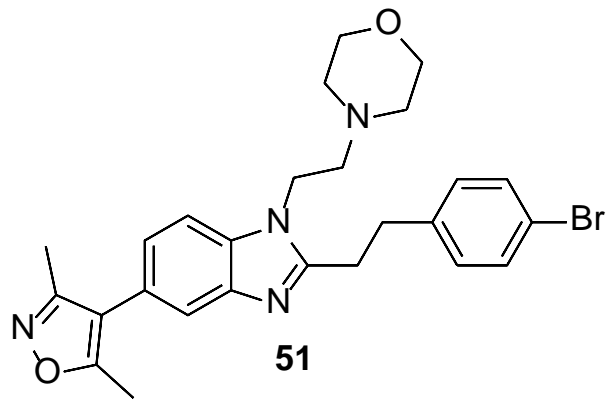

2-[2-(4-Bromophenyl)ethyl]-5-(3,5-dimethylisoxazol-4-yl)-1-(2-morpholin-4-ylethyl)-1H-

benzimidazole (51): Prepared according to general procedure A using 4-(3,5-Dimethylisoxazol-4-yl)$\mathrm{N}$-(2-morpholinoethyl)-2-nitroaniline (541 mg, $1.60 \mathrm{mmol}$ ) and 3-(4-bromophenyl)propionaldehyde ${ }^{8}$ giving 2-[2-(4-Bromophenyl)ethyl]-5-(3,5-dimethylisoxazol-4-yl)-1-(2-morpholin-4-ylethyl)-1Hbenzimidazole (400 mg, 50\%) as a light brown solid. ${ }^{1} \mathrm{H}$ NMR (400MHz, $\left.\mathrm{CDCl}_{3}\right): \delta 2.30$ (s, 3H), 2.43 (s, 3H), 2.45-2.47 (m, 4H), 2.57-2.62 (m, 2H), 3.16-3.20 (m, 2h), 3.26-3.29 (m, 2H), 3.66-3.68 (m, 4H), 4.11-4.14 (m, 2H), 7.11-7.14 (m, 3H), 7.35 (d, $J=8.4 \mathrm{~Hz}, 1 \mathrm{H}), 7.42$ (d, $J=8.4 \mathrm{~Hz}, 2 \mathrm{H}), 7.63$ (s, 1H); LC-MS m/z 509, $511(\mathrm{M}+1)^{+}$.

General Procedure C (Synthesis of $N$-arylated systems, e. g. 18):

4-\{2-[5-(3,5-Dimethylisoxazol-4-yl)-1-(2-morpholin-4-ylethyl)-1H-benzimidazol-2-yl]ethyl $\}-N, N$ dimethylaniline (18): A mixture of 2-[2-(4-Bromophenyl)ethyl]-5-(3,5-dimethylisoxazol-4-yl)-1-(2-

7 Colbon, P.; Ruan, J.; Purdie, M.; Mulholland, K.; Xiao, J. Org. Lett. 2011, 13, 5456 DOI: 10.102/ol202144z.

${ }^{8}$ Liu, J.; He, S.; Jian, T.; Dobbelaar, P.H.; Sebhat, I.K.; Lin, L.S.; Goodman, A.; Guo, C.; Guzzo, P.R.; Hadden, M.; Henderson, A.J.; Pattamana, K.; Ruenz, M.; Sargent, B.J.; Swenson, B.; Yet, L.; Tamvakopoulos, C.; Peng, Q.; Pan, J.; Kan, Y.; Palyha, O.; Kelly, T.M.; Guan, X.-M.; Howard, A.D.; Marsh, D.J.; Metzger, J.M.; Reitman, M.L.; Wyvratt, M.J.; Nargund, R.P. Bioorg. Med. Chem. Lett. 2010, 20, 2074 DOI: 10.1016/j.bmcl.2010.02.076. 
morpholin-4-ylethyl)-1H-benzimidazole (51) (26 mg, $0.05 \mathrm{mmol}$ ), $\mathrm{Pd}(\mathrm{OAc})_{2}$ (1.1 mg, $0.005 \mathrm{mmol}$ ), Ru-Phos (3.7 mg, $0.008 \mathrm{mmol}$ ), dimethylammonium chloride (25 mg, $0.31 \mathrm{mmol}$ ) and sodium tertbutoxide (44 mg, $0.46 \mathrm{mmol})$ in THF $(0.4 \mathrm{~mL})$ was heated at $70^{\circ} \mathrm{C}$ under nitrogen overnight. The reaction mixture was cooled to ambient temperature, diluted with THF and partitioned between ethyl acetate and ammonium chloride solution. The layers were separated and aqueous was extracted with ethyl acetate. The combined extracts were washed with brine. Purification of the crude residue by prep-HPLC gave $18(12.8 \mathrm{mg}, 54 \%)$ as a colorless solid. ${ }^{1} \mathrm{H}$ NMR $\left(400 \mathrm{MHz}, \mathrm{CDCl}_{3}\right): \delta 2.30(\mathrm{~s}, 3 \mathrm{H})$, 2.43 (s, 3H), 2.46-2.49 (m, 4H), $2.58(\mathrm{t}, J=6.8 \mathrm{~Hz}, 2 \mathrm{H}), 2.92(\mathrm{~s}, 6 \mathrm{H}), 3.16-3.20(\mathrm{~m}, 4 \mathrm{H}), 3.68-3.70$ (m, 4H), 4.13 (t, $J=6.8 \mathrm{~Hz}, 2 \mathrm{H}), 6.70(\mathrm{~d}, J=8.2 \mathrm{~Hz}, 2 \mathrm{H}), 7.09-7.13(\mathrm{~m}, 3 \mathrm{H}), 7.36(\mathrm{~d}, J=8.2 \mathrm{~Hz}$, 1H), 7.64 (s, 1H); LC-MS m/z $474(\mathrm{M}+1)^{+}$.

5-(3,5-Dimethylisoxazol-4-yl)-2-[2-(4-aminophenyl)ethyl]-1-(2-morpholin-4-ylethyl)-1H-

benzimidazole (17). Prepared according to general procedure $\mathrm{C}$ using ammonium chloride (500 mg, 94\%) as a yellow solid: ${ }^{1} \mathrm{H}$ NMR (400 MHz, DMSO- $\left.d_{6}\right) \delta 7.68-7.57(\mathrm{~m}, 5 \mathrm{H}), 7.31$ (dd, $J=14.2,8.1$ Hz, 3H), 7.15 (s, 1H), 7.04 (d, $J=21.2 \mathrm{~Hz}, 3 \mathrm{H}$ ), 4.60 (t, $J=7.7 \mathrm{~Hz}, 2 \mathrm{H}$ ), $4.13-4.00$ (m, 5H), 3.25 (d, $J=7.9 \mathrm{~Hz}, 2 \mathrm{H}$ ), 3.13 (t, $J=7.9 \mathrm{~Hz}, 2 \mathrm{H}), 2.34$ (s, 3H), 2.17 (s, 3H), 2.02 (s, 1H), 1.55 (q, $J=6.0 \mathrm{~Hz}$, $2 \mathrm{H}), 1.35-1.14(\mathrm{~m}, 21 \mathrm{H}), 0.85-0.72(\mathrm{~m}, 15 \mathrm{H})$.

N-(4-\{2-[5-(3,5-Dimethylisoxazol-4-yl)-1-(2-morpholin-4-ylethyl)-1H-benzimidazol-2-yl]ethyl phenyl)acetamide (19). Prepared according to general procedure C. The reaction mixture was concentrated and the residue was purified by prep-HPLC to give $19(34.7 \mathrm{mg}, 65 \%)$ as a colorless solid. ${ }^{1} \mathrm{H}$ NMR (400 MHz, CDCl $)$ ): $\delta 2.18$ (s, 3H), 2.30 (s, 3H), 2.43 (s, 3H), 2.46-2.49 (m, 4H), 2.592.62 (m, 2H), 3.16-3.28 (m, 4H), 3.66-3.69 (m, 4H), 4.11-4.14 (m, 2H), 7.12 (dd, $J=8.5,1.5 \mathrm{~Hz}, 1 \mathrm{H}$ ), 7.18-7.20 (m, 3H), 7.36 (d, $J=8.0 \mathrm{~Hz}, 1 \mathrm{H}), 7.42$ (d, $J=8.5 \mathrm{~Hz}, 2 \mathrm{H}), 7.63$ (s, 1H); LC-MS m/z 488 $(\mathrm{M}+1)^{+}$.

3-(4-\{2-[5-(3,5-Dimethylisoxazol-4-yl)-1-(2-morpholin-4-ylethyl)-1H-benzimidazol-2-yl]ethyl \}phenoxy)- $N, N$-dimethylpropan-1-amine (20). To a mixture of 9 (30 mg, $0.067 \mathrm{mmol}$ ) and potassium tert-butoxide (22.5 mg, $0.20 \mathrm{mmol})$ in DMA $(2.5 \mathrm{~mL})$ was added $\mathrm{N}$-(3bromopropyl)dimethylamine (16.6 mg, $0.10 \mathrm{mmol}$ ). The mixture was allowed to stir at $60{ }^{\circ} \mathrm{C}$ for 2 hours. The reaction mixture was cooled to room temperature and filtered. The filtrate was purified by prep-HPLC to give 20 (8.1 mg, $23 \%$ ) as colorless solid. ${ }^{1} \mathrm{H}$ NMR (400MHz, $\left.\mathrm{CD}_{3} \mathrm{OD}\right)$ : $\delta$ 2.16-2.23 (m, 2H), 2.27 (s, 3H), 2.42 (s, 3H), 2.44-2.46 (m, 4H), 2.56 (t, $J=6.5 \mathrm{~Hz}, 2 \mathrm{H}), 2.91$ (s, 6H), 3.15-3.27 (m, $4 \mathrm{H}), 3.31-3.34(\mathrm{~m}, 2 \mathrm{H}), 3.61-3.63(\mathrm{~m}, 4 \mathrm{H}), 4.07(\mathrm{t}, J=5.5 \mathrm{~Hz}, 2 \mathrm{H}), 4.22(\mathrm{t}, J=6.3 \mathrm{~Hz}, 2 \mathrm{H}), 6.86$ (d, $J$ $=8.5 \mathrm{~Hz}, 2 \mathrm{H}), 7.15$ (d, $J=8.5 \mathrm{~Hz}, 2 \mathrm{H}), 7.22(\mathrm{~d}, J=8.0 \mathrm{~Hz}, 1 \mathrm{H}), 7.54-7.58(\mathrm{~m}, 2 \mathrm{H})$; LC-MS m/z 532 $(\mathrm{M}+1)^{+}$.

5-(3,5-Dimethylisoxazol-4-yl)-1-(2-morpholin-4-ylethyl)-2-(2-pyridin-2-ylethyl)-1H-benzimidazole (21). Prepared according to general procedure A using 4-(3,5-Dimethylisoxazol-4-yl)- $\mathrm{N}$-(2- 
morpholinoethyl)-2-nitroaniline (375 mg, $1.08 \mathrm{mmol}$ ) and 2-pyridinyl-propionaldehyde ${ }^{9}$ giving 21 (74 mg, 16\%) as a yellow oil. ${ }^{1} \mathrm{H}$ NMR $\left(400 \mathrm{MHz}, \mathrm{CDCl}_{3}\right): \delta 2.27(\mathrm{~s}, 3 \mathrm{H}), 2.40(\mathrm{~s}, 3 \mathrm{H}), 2.49-2.50(\mathrm{~m}, 4 \mathrm{H})$, $2.67(\mathrm{t}, J=6.8 \mathrm{~Hz}, 2 \mathrm{H}), 3.38-3.48(\mathrm{~m}, 4 \mathrm{H}), 3.65-3.67(\mathrm{~m}, 4 \mathrm{H}), 2.24(\mathrm{t}, J=6.8 \mathrm{~Hz}, 2 \mathrm{H}), 7.09-7.15(\mathrm{~m}$, 2H), 7.22 (d, $J=8.0 \mathrm{~Hz}, 1 \mathrm{H}), 7.34$ (d, $J=8.4 \mathrm{~Hz}, 1 \mathrm{H}), 7.56-7.60$ (m, 2H), 8.54 (d, $J=4.4 \mathrm{~Hz}, 1 \mathrm{H})$; LC-MS m/z $432(\mathrm{M}+1)^{+}$.

5-(3,5-Dimethylisoxazol-4-yl)-1-(2-morpholin-4-ylethyl)-2-(2-pyridin-3-ylethyl)-1H-benzimidazole (22). Prepared according to general procedure A using 4-(3,5-Dimethylisoxazol-4-yl)- $N$-(2morpholinoethyl)-2-nitroaniline (332 mg, $0.96 \mathrm{mmol}$ ) and 3-pyridinyl-propionaldehyde ${ }^{10}$ giving 22 (183 mg, 37\%) as a yellow oil. ${ }^{1} \mathrm{H}$ NMR (400MHz, $\left.\mathrm{CDCl}_{3}\right): \delta 2.29(3 \mathrm{H}), 2.42(\mathrm{~s}, 3 \mathrm{H}), 2.44-2.46$ (m, $4 \mathrm{H}), 2.61(\mathrm{t}, J=6.8 \mathrm{~Hz}, 2 \mathrm{H}), 3.19-3.24(\mathrm{~m}, 2 \mathrm{H}), 3.32-3.36(\mathrm{~m}, 2 \mathrm{H}), 3.64-3.66(\mathrm{~m}, 4 \mathrm{H}), 4.14(\mathrm{t}, J=6.8$ Hz, 2H), 7.11-7.14 (m, 1H), 7.22-7.26 (m, 1H), 7.35 (d, $J=8.0 \mathrm{~Hz}, 1 \mathrm{H}), 7.58$ (d, $J=8.0 \mathrm{~Hz}, 1 \mathrm{H}), 7.62$ (d, $J=0.8 \mathrm{~Hz}, 1 \mathrm{H}), 8.47-8.49(\mathrm{~m}, 1 \mathrm{H}), 8.53$ (d, $J=1.6 \mathrm{~Hz}, 1 \mathrm{H})$; LC-MS m/z $432(\mathrm{M}+1)^{+}$.

5-(3,5-Dimethylisoxazol-4-yl)-1-(2-morpholin-4-ylethyl)-2-(2-pyridin-4-ylethyl)-1H-benzimidazole (23). Prepared according to general procedure A using 4-(3,5-Dimethylisoxazol-4-yl)- $N$-(2morpholinoethyl)-2-nitroaniline (498 mg, $1.44 \mathrm{mmol}$ ) and 4-pyridinyl-propionaldehyde ${ }^{10}$ giving 23 (159 mg, 21\%) as a yellow oil. ${ }^{1} \mathrm{H}$ NMR $\left(400 \mathrm{MHz}, \mathrm{CDCl}_{3}\right): \delta 2.29(\mathrm{~s}, 3 \mathrm{H}), 2.43(\mathrm{~s}, 3 \mathrm{H}), 2.45-2.48(\mathrm{~m}$, $4 \mathrm{H}), 2.65(\mathrm{t}, J=6.8 \mathrm{~Hz}, 2 \mathrm{H}), 3.21-3.25(\mathrm{~m}, 2 \mathrm{H}), 3.33-3.37(\mathrm{~m}, 2 \mathrm{H}), 3.65-3.67(\mathrm{~m}, 4 \mathrm{H}), 4.15-4.18(\mathrm{~m}$, 2H), 7.13-7.15 (m, 1H), 7.20 (d, $J=6.0 \mathrm{~Hz}, 2 \mathrm{H}), 7.25-7.35$ (m, 1H), 7.63 (d, $J=0.8 \mathrm{~Hz}, 1 \mathrm{H}), 8.53$ (d, $J=6.0 \mathrm{~Hz}, 2 \mathrm{H})$; LC-MS $\mathrm{m} / \mathrm{z} 432(\mathrm{M}+1)^{+}$.

5-(3,5-Dimethylisoxazol-4-yl)-2-[2-(1H-indol-3-yl)ethyl]-1-(2-morpholin-4-ylethyl)-1H-benzimidazole (24). Prepared according to general procedure A using 4-(3,5-Dimethylisoxazol-4-yl)- $N$-(2morpholinoethyl)-2-nitroaniline (35 mg, $0.10 \mathrm{mmol})$ and 2-(1H-indol-3-yl)propionaldehyde ${ }^{10}$ giving 24 (23 mg, 49\%) as a yellow solid. ${ }^{1} \mathrm{H}$ NMR (400MHz, CD $\left.3 \mathrm{OD}\right): \delta 2.30$ (s, 3H), 2.47 (s, 3H), $2.70-$ $3.20(\mathrm{~m}, 6 \mathrm{H}), 3.52-3.54(\mathrm{~m}, 2 \mathrm{H}), 3.72-3.74(\mathrm{~m}, 2 \mathrm{H}), 3.91(\mathrm{~m}, 4 \mathrm{H}), 4.61-4.63(\mathrm{~m}, 2 \mathrm{H}), 7.04-7.07$ (m, 2H), 7.18 (m, 1H), 7.44 (d, $J=8.4 \mathrm{~Hz}, 1 \mathrm{H}), 7.56$ (d, $J=8.0 \mathrm{~Hz}, 1 \mathrm{H}), 7.61(\mathrm{~d}, J=8.8 \mathrm{~Hz}, 1 \mathrm{H}), 7.78$ (s, $1 \mathrm{H}), 8.12$ (d, $J=4.8 \mathrm{~Hz}, 1 \mathrm{H})$, indole $\underline{\mathrm{H}}$ not observed; LC-MS m/z $470(\mathrm{M}+1)^{+}$.

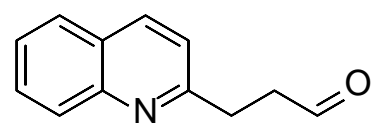

52

${ }^{9}$ Kitbunnadaj, R.; Zuiderveld, O.P.; Christophe, B.; Hulscher, S.; Menge, W.; Gelens, E.; Snip, E.; Bakker, R.A.; Celanire, S.; Gillard, M.; Talaga, P.; Timmerman, H.; Leurs, R. J. Med. Chem. 2004, 47, 2414 DOI: $10.1021 / j m 049932 u$.

${ }^{10}$ Hobley, G.; McKelvie, J.C.; Harmer, J.E.; Howe, J.; Oyston, P.C.F.; Roach, P.L. Bioorg. Med. Chem. Lett. 2012, 22, 3079 DOI: 10.1016/j.bmcl.2012.03.072. 
3-(Quniolin-2-yl)propionaldehyde (52): Prepared according to general procedure B using 2bromoquinoline (1.7 g, $8.17 \mathrm{mmol})$. The crude aldehyde (500 $\mathrm{mg}, 33 \%)$ obtained as a yellow oil was used directly in the next reaction.

2-\{2-[5-(3,5-Dimethylisoxazol-4-yl)-1-(2-morpholin-4-ylethyl)-1H-benzimidazol-2-yl]ethyl\}quinoline (25). Prepared according to general procedure A using 3-(Quniolin-2-yl)propionaldehyde (500 mg, $2.70 \mathrm{mmol}$ ) giving 25 (447 $\mathrm{mg})$ as a brown oil. LC-MS m/z $482(\mathrm{M}+1)^{+}$.

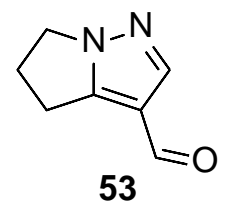

5,6-Dihydro-4H-pyrrolo[1,2-b]pyrazole-3-carboxaldehyde (53): To a mixture of 5,6-dihydro-4Hpyrrolo[1,2-b]pyrazole ${ }^{11}$ (55.5 g, $0.51 \mathrm{~mol}$ ), DMF (76 g, $1.04 \mathrm{~mol}$ ) in 1,2-dichloroethane (550 mL) was added $\mathrm{POCl}_{3}(160 \mathrm{~g}, 1.05 \mathrm{~mol})$ dropwise at $4 \sim 7{ }^{\circ} \mathrm{C}$. The reaction was heated to reflux for 4 hours, and then allowed to stir at room temperature overnight. The mixture was poured into a mixture of ice water $(2.4 \mathrm{~L})$ and anhydrous sodium acetate $(267 \mathrm{~g})$ and stirred at $25^{\circ} \mathrm{C}$ for 1 hour. The organic layer was separated and the aqueous layer was extracted with 1,2-dichloroethane $(6 \times 150 \mathrm{~mL})$. The combined organic layers were washed with saturated $\mathrm{NaHCO}_{3}(2 \times 200 \mathrm{~mL})$, dried over $\mathrm{Na}_{2} \mathrm{SO}_{4}$ and concentrated in vacuo. Pre-purification by column chromatography (10-50\% ethyl acetate/petroleum ether), followed by re-crystallization from $i-\mathrm{PrOH}$ at $-35{ }^{\circ} \mathrm{C}$ afforded pure 5,6-Dihydro- $4 \mathrm{H}$ pyrrolo[1,2-b]pyrazole-3-carboxaldehyde (35 g, 45.5\%) as an yellow liquid at ambient temperature. ${ }^{1} \mathrm{H}$ NMR (300 MHz, CDCl 3 ): $\delta 2.71(\mathrm{~m}, 2 \mathrm{H}), 3.12(\mathrm{t}, J=7.2 \mathrm{~Hz}, 2 \mathrm{H}), 4.18(\mathrm{t}, J=7.2 \mathrm{~Hz}, 2 \mathrm{H}), 7.93$ (s, 1H); LC-MS m/z $137(\mathrm{M}+1)^{+}$.

4-(2-(5-(3,5-dimethylisoxazol-4-yl)-2-(2-(isoquinolin-4-yl)ethyl)-1H-benzo[d]imidazol-1-

yl)ethyl)morpholine (26). Prepared according to general procedure A giving 26 (55 mg, 78\%) as a yellow oil. ${ }^{1} \mathrm{H}$ NMR (400 MHz, $\mathrm{CDCl}_{3}$ ) 2.31 (s, 3H), 2.33-2.35 (m, 4H), 2.44 (s, 3H), 2.52 (dd, $J=$ 7.0, $6.6 \mathrm{~Hz}, 2 \mathrm{H}), 3.34-3.38(\mathrm{~m}, 2 \mathrm{H}), 3.57-3.59(\mathrm{~m}, 4 \mathrm{H}), 3.73-3.77(\mathrm{~m}, 2 \mathrm{H}), 4.04(\mathrm{t}, J=6.0 \mathrm{~Hz}, 2 \mathrm{H})$, 7.13 (dd, $J=8.2,1.6 \mathrm{~Hz}, 1 \mathrm{H}$ ), 7.33 (d, $J=8.2 \mathrm{~Hz}, 1 \mathrm{H}$ ), 7.63-7.67 (m, 2H), 7.75 (ddd, $J=8.2,7.0,1.3$ Hz, 1H), 8.03 (d, $J=8.2 \mathrm{~Hz}, 1 \mathrm{H}), 8.12(\mathrm{~d}, J=8.2 \mathrm{~Hz}, 1 \mathrm{H}), 8.43(\mathrm{~s}, 1 \mathrm{H}), 9.18(\mathrm{~s}, 1 \mathrm{H})$; HR-MS $(\mathrm{M}+\mathrm{H})^{+}$ $\mathrm{m} / \mathrm{z}$ calc'd. 482.2551; found 482.2550 .

2-(5,6-dihydro-4H-pyrrolo[1,2-b]pyrazol-3-yl)-5-(3,5-dimethylisoxazol-4-yl)-1-(2-morpholin-4ylethyl)-1H-benzimidazole (27). Prepared according to general procedure A using 4-(3,5Dimethylisoxazol-4-yl)- $\mathrm{N}$-(2-morpholinoethyl)-2-nitroaniline (2.42 g, $7.0 \mathrm{mmol})$ and 5,6-Dihydro- $4 \mathrm{H}$ -

${ }^{11}$ Kulinkovich, O.; Masalov, N.; Tyvorskii, V.; De Kimpe, N.; Keppens, M. Tetrahedron Lett. 1996, 37, 1095 DOI: 10.1016/0040-4039(95)02313-5. 
pyrrolo[1,2-b]pyrazole-3-carboxaldehyde (2.95 g, $21.7 \mathrm{mmol})$ giving $27(1.2 \mathrm{~g}, 40 \%)$ as a colorless solid. ${ }^{1} \mathrm{H}$ NMR (400MHz, $\left.\mathrm{CDCl}_{3}\right): \delta 2.31$ (s, 3H), 2.44 (s, 3H), 2.51-2.54 (m, 4H), 2.72-2.76 (m, 2H), $2.84(\mathrm{t}, J=8.2 \mathrm{~Hz}, 2 \mathrm{H}), 3.26(\mathrm{t}, J=7.2 \mathrm{~Hz}, 2 \mathrm{H}), 3.68-3.71(\mathrm{~m}, 4 \mathrm{H}), 4.27(\mathrm{t}, J=7.2 \mathrm{~Hz}, 2 \mathrm{H}), 4.46(\mathrm{t}, J$ $=7.2 \mathrm{~Hz}, 2 \mathrm{H}), 7.14$ (dd, $J=8.4,1.6 \mathrm{~Hz}, 1 \mathrm{H}), 7.44$ (d, $J=8.0 \mathrm{~Hz}, 1 \mathrm{H}), 7.62$ (d, $J=0.8 \mathrm{~Hz}, 1 \mathrm{H}), 8.00$ (s, 1H).

2-(5-(3,5-dimethylisoxazol-4-yl)-2-phenethyl-1H-benzo[d] imidazol-1-yl)-1-morpholinoethan-1-one (28). Prepared according to general procedure A giving 28 (13 mg, 21\%) as a white solid. ${ }^{1} \mathrm{H}$ NMR $\left(400 \mathrm{MHz}, \mathrm{CDCl}_{3}\right): \delta 2.31$ (s, 3H), $2.44(\mathrm{~s}, 3 \mathrm{H}), 3.26(\mathrm{t}, J=7.2 \mathrm{~Hz}, 2 \mathrm{H}), 3.18-3.71(\mathrm{~m}, 4 \mathrm{H}), 4.27(\mathrm{t}, J=$ $7.2 \mathrm{~Hz}, 2 \mathrm{H}), 4.46$ (t, $J=7.2 \mathrm{~Hz}, 2 \mathrm{H}), 7.14$ (dd, $J=8.4,1.6 \mathrm{~Hz}, 1 \mathrm{H}), 7.44$ (d, $J=8.0 \mathrm{~Hz}, 1 \mathrm{H}), 7.62$ (d, $J=0.8 \mathrm{~Hz}, 1 \mathrm{H}), 8.00(\mathrm{~s}, 1 \mathrm{H})$.

4-(2-(5-(3,5-dimethylisoxazol-4-yl)-2-((2S,3R)-2-(4-methoxyphenyl)tetrahydrofuran-3-yl)-1H-

benzo[d] imidazol-1-yl)ethyl)morpholine (29). Prepared according to general procedure $A$ as a racemate which was then separated using chiral SFC conditions (Lux cellulose-3 $250 \mathrm{~mm} \times 21.2 \mathrm{~mm}$, $5 \mu \mathrm{m}, 80 \mathrm{~mL} / \mathrm{min}$, first eluting peak, stereochemistry arbitrarily assigned) giving 29 (45 mg, 17\%) as a white solid. ${ }^{1} \mathrm{H}$ NMR (400 MHz, DMSO-d6) $\delta$ ppm 2.14 (d, J=7.02 Hz, 1 H) 2.21 - 2.34 (m, 8 H) 2.41 (s, 4 H) 3.45 (t, J=4.49 Hz, 4 H) 3.56 - 3.66 (m, 1 H) 3.71 (s, 3 H) 3.92 - 4.05 (m, 1 H) 4.05 - 4.29 (m, $3 \mathrm{H}) 5.14$ (d, J=8.59 Hz, 1 H) 6.87 (d, J=8.98 Hz, 2 H) 7.18 (dd, J=8.20, 1.56 Hz, 1 H) 7.24 (d, J=8.98 $\mathrm{Hz}, 2 \mathrm{H}) 7.55$ (d, J=8.59 Hz, $1 \mathrm{H}) 7.63$ (d, J=1.56 Hz, $1 \mathrm{H}$ ); the second eluting peak (30) under these chiral SFC conditions was recovered as $30 \mathrm{mg}(11 \%)$ as a white solid having an identical ${ }^{1} \mathrm{HNMR}$ signature.

General Approach to compounds 31-32 
<smiles>O=C1NC(CO)CC1Br</smiles>

54 $\stackrel{(a)}{\longrightarrow}$<smiles>O=C1N[C@H](Cc2ccccc2)C[C@H]1CN1CCOCC1</smiles>

$\stackrel{(b)}{\longrightarrow}$<smiles>Cc1noc(C)c1-c1ccc(N2C(=O)[C@@H](Cc3ccccc3)C[C@H]2CN2CCOCC2)c([N+](=O)[O-])c1</smiles><smiles>Cc1noc(C)c1-c1ccc(N2C(=O)[C@H](Cc3ccccc3)C[C@H]2CN2CCOCC2)c(N)c1</smiles><smiles>Cc1noc(C)c1-c1ccc2c(c1)nc1n2[C@@H](CN2CCOCC2)C[C@H]1Cc1ccccc1</smiles>

31; $X=H, Y=B n(26 \%)$

32; $X=B n, Y=H(22 \%)$

(a) $\mathrm{PPh}_{3}$ (resin), $\mathrm{I}_{2}$ ' morpholine, TEA, $50{ }^{\circ} \mathrm{C}, 16 \mathrm{~h}$; 56\% (b) 4-(4-fluoro-3-nitrophenyl)-3,5-dimethylisoxazole, $\mathrm{Cs}_{2} \mathrm{CO}_{3}$, acetone, $90{ }^{\circ} \mathrm{C}, 20 \mathrm{~h} ; 11 \%$ (c) $\mathrm{Na}_{2} \mathrm{~S}_{2} \mathrm{O}_{4}$, aq. EtOH, $80{ }^{\circ} \mathrm{C}, 16 \mathrm{~h} ; 99 \%$ (d) AcOH, DMF, $150{ }^{\circ} \mathrm{C}, 2 \mathrm{~h} ; 56 \%$ (e) SFC separation

Step 1. (5S)-3-benzyl-5-(morpholinomethyl)pyrrolidin-2-one (55): To a solution of benzyl-5(hydroxymethyl)pyrrolidin-2-one ${ }^{12}$ (54) $(1.2 \mathrm{~g}, 5.9 \mathrm{mmol})$ in THF (25 mL) was added solid-supported triphenylphosphine (70.8 g, $23.6 \mathrm{mmol}, 3 \mathrm{mmol} / \mathrm{g}$ loading), $\mathrm{I}_{2}(3 \mathrm{~g}, 11.8 \mathrm{mmol})$, triethylamine $(3 \mathrm{~g}$, $29.5 \mathrm{mmol}$ ) and morpholine $(5.1 \mathrm{~g}, 59 \mathrm{mmol})$ and the reaction was stirred for 16 hours at $50{ }^{\circ} \mathrm{C}$ under nitrogen atmosphere. The reaction was allowed to cool to room temperature and filtered. The filtrate was concentrated in vacuum and the residue was purified by flash chromatography $(0 \sim 7 \%$ of $\mathrm{MeOH}$ in DCM) to give the titled compound (900 mg, 56\%) as a colorless oil: LCMS m/z [M + H+]: 274.9.

Step 2. (5S)-3-benzyl-1-(4-(3,5-dimethylisoxazol-4-yl)-2-nitrophenyl)-5-(morpholinomethyl)pyrrolidin2-one (56): To a mixture of 3-benzyl-5-(morpholinomethyl)pyrrolidin-2-one (600 mg, $2.18 \mathrm{mmol}$ ), 4(4-fluoro-3-nitrophenyl)-3,5-dimethylisoxazole ${ }^{13}(600 \mathrm{mg}, 2.54 \mathrm{mmol}$ ) and cesium carbonate (3.6 g,

12 Beard, M. J.; Bailey, J. H.; Cherry, D. T.; Moloney, M. G.; Shim, S. B.; Statham, K. A.; Bamford, M. J.; Lamont, R. B. Tetrahedron, 1996, 52, 3719-40.

13 Hay, D. A.; Fedorov, O.; Martin, S.; Singleton, D. C.; Tallant, C.; Wells, C.; Picaud, S.; Philpott, M.; Monteiro, O. P.; Rogers, C. M., et al. J. Am. Chem. Soc. 2014, 136, 9308-19. 
$11 \mathrm{mmol}$ ) in acetone ( $20 \mathrm{~mL}$ ) was stirred for 20 hours at $90{ }^{\circ} \mathrm{C}$. The reaction was then allowed to cool to room temperature and the mixture was filtered through a pad of silica. The filtrate was concentrated under reduced pressure to give the titled compound (120 mg, $56 \%$ ) as colorless oil which was taken forward without any further purification or characterization.

Step $3 . \quad$ (5S)-1-(2-amino-4-(3,5-dimethylisoxazol-4-yl)phenyl)-3-benzyl-5(morpholinomethyl)pyrrolidin-2-one (57). A mixture of (5S)-3-benzyl-1-(4-(3,5-dimethylisoxazol-4yl)-2-nitrophenyl)-5-(morpholinomethyl)pyrrolidin-2-one (100 mg, $0.2 \mathrm{mmol}$ ) and $\mathrm{Na}_{2} \mathrm{~S}_{2} \mathrm{O}_{4}$ (174 mg, 1 $\mathrm{mmol})$ in $\mathrm{EtOH} / \mathrm{H}_{2} \mathrm{O}(4 \mathrm{~mL} / 1 \mathrm{~mL})$ was stirred at $80{ }^{\circ} \mathrm{C}$ for 16 hours. The reaction mixture was then concentrated under reduced pressure and the crude residue $(100 \mathrm{mg})$ was taken forward without any further purification or characterization.

Step 4. 4-(((1S)-3-benzyl-6-(3,5-dimethylisoxazol-4-yl)-2,3-dihydro-1H-benzo[d]pyrrolo[1,2a]imidazol-1-yl)methyl)morpholine (58). A mixture of (5S)-1-(2-amino-4-(3,5-dimethylisoxazol-4yl)phenyl)-3-benzyl-5-(morpholinomethyl)pyrrolidin-2-one (100 mg, $0.2 \mathrm{mmol}$ ) in DMF/AcOH (10 $\mathrm{mL} / 0.5 \mathrm{~mL}$ ) was heated in microwave vessel for 2 hours at $150^{\circ} \mathrm{C}$. The mixture was then diluted with water $(10 \mathrm{~mL})$ and extracted three times with ethyl acetate $(20 \mathrm{~mL})$. The combined organic layer was dried over $\mathrm{Na}_{2} \mathrm{SO}_{4}$, filtered and concentrated under reduced pressure. The crude residue was purified by flash silica chromatography (1:1 petroleum ether:EtOAc) to give a mixture of the titled compounds (50 mg, 56\%) as a yellow solid: LCMS m/z [M + H+]: 443.2 .

Step 5: 4-(((1S,3S)-3-benzyl-6-(3,5-dimethylisoxazol-4-yl)-2,3-dihydro-1H-benzo[d]pyrrolo[1,2a]imidazol-1-yl)methyl)morpholine (31) and 4-(((1S,3R)-3-benzyl-6-(3,5-dimethylisoxazol-4-yl)-2,3dihydro-1H-benzo[d] pyrrolo[1,2-a] imidazol-1-yl)methyl)morpholine (32): The mixture of titled compounds $(50 \mathrm{mg})$ was purified by SFC chromatography using the following conditions: ChiralpakAD (250x30mm) $20 \mathrm{~mm}, 25 \% \mathrm{MeOH}\left(\mathrm{NH}_{4} \mathrm{OH}\right), 80 \mathrm{~mL} / \mathrm{min}$. Two peaks eluted which were resolved using the following conditions: Chiralpak AD-3 (50x4.6mm), 3mm, MeOH (0.05\% DEA) in $\mathrm{CO}_{2}$ (540\%), $4 \mathrm{~mL} / \mathrm{min}, 4 \mathrm{~min}$.

The first peak eluted at $1.51 \mathrm{~min}$ and was assigned as 4-(((1S,3R)-3-benzyl-6-(3,5dimethylisoxazol-4-yl)-2,3-dihydro-1H-benzo[d]pyrrolo[1,2-a]imidazol-1-yl)methyl)morpholine (7): LCMS m/z [M + H+]: 443.2; ${ }^{1} \mathrm{HNMR}\left(\mathrm{CDCl}_{3}\right) \mathrm{d}$ 7.67-7.65 (m, $\left.1 \mathrm{H}\right), 7.61(\mathrm{~s}, 1 \mathrm{H}), 7.32-7.29(\mathrm{~m}, 2 \mathrm{H})$, 7.26-7.21 (m, 3H), 7.10-7.08 (m, 1H), 4.45 (br s, 1H), 3.75-3.65 (m, 5H), 3.56-3.53 (m, 1H), 2.84-2.71 (m, $1 \mathrm{H}), 2.55-2.40(\mathrm{~m}, 10 \mathrm{H}), 2.27$ (s, 3H).

The second peak eluted at $1.66 \mathrm{~min}$ and was assigned as 4-(((1S,3S)-3-benzyl-6-(3,5dimethylisoxazol-4-yl)-2,3-dihydro-1H-benzo[d]pyrrolo[1,2-a]imidazol-1-yl)methyl)morpholine (6): LCMS m/z [M + H+]: 443.2; ${ }^{1} \mathrm{HNMR}\left(\mathrm{CDCl}_{3}\right) \mathrm{d} 7.89-7.87(\mathrm{~m}, 1 \mathrm{H}), 7.61(\mathrm{~s}, 1 \mathrm{H}), 7.30-7.22(\mathrm{~m}, 5 \mathrm{H})$, 7.10-7.09 (m, 1H), 4.52-4.49 (m, 1H), 3.79-3.77 (m, 4H), 3.57-3.53 (m, 2H), 2.98-2.97 (m, 1H), 2.77$2.66(\mathrm{~m}, 1 \mathrm{H}), 2.65-2.63(\mathrm{~m}, 1 \mathrm{H}), 2.59-2.57(\mathrm{~m}, 3 \mathrm{H}), 2.47-2.40(\mathrm{~m}, 6 \mathrm{H}), 2.30(\mathrm{~s}, 3 \mathrm{H})$.

\section{Preparation of compounds 33-38}

Derivatives 33-38 prepared in library format using General Procedure A (benzimidazole formation) substituting the appropriate boronic acid/pinacol borane, arylpropionic aldehyde, and onitrofluoroarene within the specified sequence to produce compounds 33-38 as exemplified by structure 33 below: 
General Approach to the Construction of indoles/azaindoles 39-41.

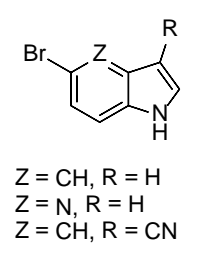

59

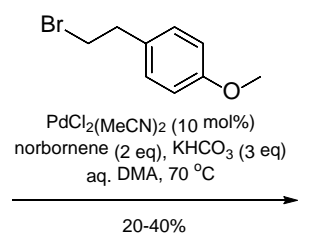

$20-40 \%$

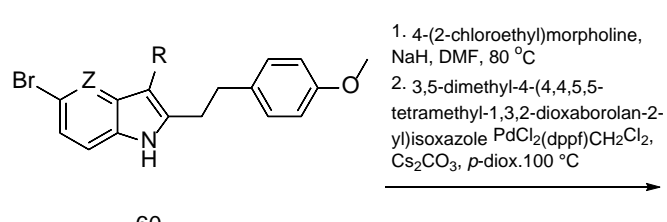

60

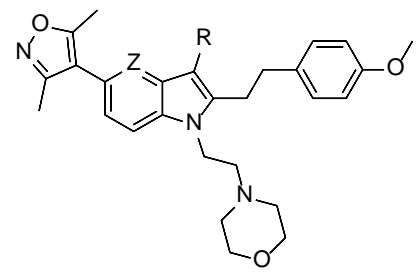

39: $\mathrm{Z}=\mathrm{CH}, \mathrm{R}=\mathrm{H}$

41: $Z=N, R=H$

40: $\mathrm{Z}=\mathrm{CH}, \mathrm{R}=\mathrm{CN}$

Step 1: 5-bromo-2-(4-methoxyphenethyl)-1H-pyrrolo[3,2-b]pyridine. ${ }^{14}$ (60): To a RB flask charged with 5-bromo-4-azaindole (250 mg, $1.27 \mathrm{mmol}$ ), norbornene (239 $\mathrm{mg}, 2.54 \mathrm{mmol}$ ), potassium bicarbonate (381 mg, $3.81 \mathrm{mmol}$ ), and bis(acetonitrile)dichloropalladium (ii) (65.9 mg, $0.254 \mathrm{mmol}$ ) was added $4 \mathrm{~mL}$ of aq DMA $(1 \mathrm{~N})$. The mixture was sparged with nitrogen gas for 2-3 minutes prior to the dropwise addition of 1-(2-bromoethyl)-4-methoxybenzene (409 mg, $1.90 \mathrm{mmol}$ ) over the course of 1 minute. The mixture was then swept with nitrogen gas and then heated to $70 \mathrm{C}$ for $20 \mathrm{~h}$. The mixture was then cooled to rt, diluted with ethyl acetate $(10 \mathrm{~mL})$ and then washed three times with water. The organics were collected, washed with brine, dried with sodium sulfate, filtered, and concentrated under reduced pressure to give a brown oily residue which was purified by flash chromatography (0-100\% EtOAc in Heptane over 25 mins) to give $84 \mathrm{mg}$ (20\%) of the titled compound as a brown oil: 1H NMR (400 MHz, Chloroform-d) $\delta 7.61(\mathrm{~d}, \mathrm{~J}=8.3 \mathrm{~Hz}, 1 \mathrm{H}), 7.16(\mathrm{~d}, \mathrm{~J}=8.3 \mathrm{~Hz}, 2 \mathrm{H}), 7.07$ (d, J = 8.3 Hz, 1H), $6.89-6.82$ (m, 2H), 6.54 (s, 1H), 4.15 (t, J = 7.1 Hz, 2H), $3.80(\mathrm{~s}, 3 \mathrm{H}), 3.68$ (t, J = 4.5 Hz, 4H), 3.09 (s, 4H), 2.57 (d, J = 21.1 Hz, 5H), 2.44 (d, J = 16.9 Hz, 7H), 1.91 (s, 2H), 1.26 (d, J = 5.7 Hz, 2H), 1.24 (s, 13H). LCMS m/z [M+H+]: 332.9.

Steps 2 \& 3: 4-(2-(5-(3,5-dimethylisoxazol-4-yl)-2-(4-methoxyphenethyl)-1H-pyrrolo[3,2-b]pyridin-1yl)ethyl)morpholine (41): To an oven-dried RB flask charged with DMF (2 mL) was added 60\% sodium hydride in dispersion oil (29.0 $\mathrm{mg}, 0.725 \mathrm{mmol})$ at RT. To this mixture was then dropwise added a solution of 5-bromo-2-(4-methoxyphenethyl)-1H-pyrrolo[3,2-b]pyridine (40 mg, $0.12 \mathrm{mmol}$ ) in $1 \mathrm{~mL}$ of DMF at rt, and subsequently 4-(2-chloroethyl)morpholine (67.4 mg, $0.362 \mathrm{mmol}$ ). The mixture was allowed to stir at rt for five minutes prior to heating to $80 \mathrm{C}$ for 45 minutes. The mixture was then cooled to rt and poured into water. The mixture was then extracted three times with ethyl acetate and the combined organics were washed with water, brine, dried with sodium sulfate, filtered, and concentrated under reduced pressure to give $12 \mathrm{mg}$ (22\%) of 4-(2-(5-bromo-2-(4methoxyphenethyl)-1H-pyrrolo[3,2-b]pyridin-1-yl)ethyl)morpholine as a yellow oil: 1H NMR (400 MHz, Chloroform-d) $\delta 7.95(\mathrm{~s}, 1 \mathrm{H}), 7.35(\mathrm{~d}, \mathrm{~J}=8.5 \mathrm{~Hz}, 3 \mathrm{H}), 7.14-7.01(\mathrm{~m}, 9 \mathrm{H}), 6.80-6.72(\mathrm{~m}, 6 \mathrm{H})$, 6.39 (s, 3H), 4.01 (s, 1H), 3.72 (s, 8H), 3.58 (s, 11H), 2.98 (q, J = 3.3 Hz, 12H), 2.88 (s, 3H), 2.81 (s, $3 \mathrm{H}), 2.47(\mathrm{t}, \mathrm{J}=6.9 \mathrm{~Hz}, 6 \mathrm{H}), 2.33(\mathrm{~s}, 11 \mathrm{H})$. This product was immediately carried forward to the next step in the synthetic sequence without further purification or characterization.

${ }^{14}$ For studies related to the C-H insertion chemistry employed to furnish these systems, see: Jiao, L.; Bach, T. J. Am. Chem. Soc. 2012, 134, 14563-72. 
To a RB flask charged with $8 \mathrm{mg}(0.02 \mathrm{mmol})$ of 4-(2-(5-bromo-2-(4-methoxyphenethyl)-1Hpyrrolo[3,2-b]pyridin-1-yl)ethyl)morpholine from the previous synthetic operation was added $0.5 \mathrm{~mL}$ of 1:1 ethanol/water. To this mixture was sequentially added 3,5-dimethyl-4-(4,4,5,5-tetramethyl1,3,2-dioxaborolan-2-yl)isoxazole $(6.00 \mathrm{mg}, 0.027 \mathrm{mmol})$, palladium acetate $(0.40 \mathrm{mg}, 0.002 \mathrm{mmol})$, 2-dicyclohexylphosphino-2',6'-diisopropoxybiphenyl (RUPHOS ${ }^{\circledR}, 1.40 \mathrm{mg}, 0.003 \mathrm{mmol}$ ), sodium carbonate $(5.70 \mathrm{mg}, 0.054 \mathrm{mmol})$, and $0.5 \mathrm{~mL}$-dioxane. The mixture was then heated to $100 \mathrm{C}$ for 2 $\mathrm{h}$, then cooled to rt and poured into water. The mixture was then extracted with ethyl acetate and then the combined organics were washed with water, brine, then dried with sodium sulfate, filtered, and concentrated to give an oily residue which was purified by flash chromatography (0-100\% EtOAc in Heptane over $12 \mathrm{mins})$. The major fraction was collected and concentrated to give $2.6 \mathrm{mg}$ (30\%) the titled compound (41) as a pale yellow solid: $1 \mathrm{H}$ NMR $(400 \mathrm{MHz}$, Chloroform-d) $\delta 7.61(\mathrm{~d}, \mathrm{~J}=8.3 \mathrm{~Hz}$, 1H), 7.16 (d, J = 8.3 Hz, 2H), 7.07 (d, J = 8.3 Hz, 1H), $6.89-6.82$ (m, 2H), $6.54(\mathrm{~s}, 1 \mathrm{H}), 4.15$ (t, J = $7.1 \mathrm{~Hz}, 2 \mathrm{H}), 3.80$ (s, 3H), 3.68 (t, J = $4.5 \mathrm{~Hz}, 4 \mathrm{H}), 3.09$ (s, 4H), 2.57 (d, J = $21.1 \mathrm{~Hz}, 5 \mathrm{H}), 2.44$ (d, J = $16.9 \mathrm{~Hz}, 7 \mathrm{H}), 1.91$ (s, 2H), 1.26 (d, J = 5.7 Hz, 2H), 1.24 (s, 13H). LCMS m/z [M + H+]: 461.2.

4-(2-(5-(3,5-dimethylisoxazol-4-yl)-2-(4-methoxyphenethyl)-1H-indol-1-yl)ethyl)morpholine (39) was prepared in a fashion similar to that of 41: $1 \mathrm{H}$ NMR $(400 \mathrm{MHz}$, Chloroform-d) $\delta 7.37-7.27(\mathrm{~m}, 1 \mathrm{H})$, $7.17-7.05$ (m, 1H), 6.95 (dt, J = 8.4, 3.1 Hz, 1H), $6.83-6.73$ (m, 1H), 6.27 (s, 1H), 4.13 (t, J = 7.5 Hz, 2H), 3.73 (s, 3H), 3.64 (t, J = 4.7 Hz, 1H), 2.98 (s, 3H), 2.57 (t, J = 7.4 Hz, 1H), 2.44 (t, J = 4.7 Hz, 1H), 2.33 (s, 0H), 2.21 (s, 3H), $2.00-1.92(\mathrm{~m}, 1 \mathrm{H}), 1.52$ (t, J = 8.2 Hz, 2H), 1.18 (d, J = 9.0 Hz, 1H), $1.14-1.00$ (m, 1H), 0.96 (dd, $\mathrm{J}=18.3,6.0 \mathrm{~Hz}, 1 \mathrm{H})$.

5-(3,5-dimethylisoxazol-4-yl)-2-(4-methoxyphenethyl)-1-(2-morpholinoethyl)-1H-indole-3-carbonitrile (40) was prepared in a fashion similar to that of 41: $1 \mathrm{H}$ NMR $(400 \mathrm{MHz}$, Chloroform-d) $\delta 7.58(\mathrm{~d}, \mathrm{~J}=$ $1.5 \mathrm{~Hz}, 1 \mathrm{H}), 7.40$ (d, J = 8.5 Hz, 1H), $7.21-7.07$ (m, 3H), 6.86 (d, J = 8.5 Hz, 2H), 4.06 (t, J = 7.0 Hz, 2H), 3.82 (s, 3H), 3.71 (t, J = 4.6 Hz, 4H), 3.29 (t, J = 7.6 Hz, 2H), 3.09 (t, J = 7.6 Hz, 2H), 2.60 (t, J = $7.0 \mathrm{~Hz}, 2 \mathrm{H}), 2.47$ (d, J = 5.4 Hz, 7H), 2.32 (s, 3H).

\section{Acknowledgment}

We thank the Analytical Division and Sample Logistics at Pfizer Cambridge for their assistance on the project. RAD thanks the HPC team (Nicholas Labello and Vassilios Pantazopoulos) for the computational infrastructural support and Brajesh Rai and Jacquelyn Klug-McLeod for their atropisomer protocol. The SGC is a registered charity (number 109773 7) that receives funds from AbbVie, Bayer Pharma AG, Boehringer Ingelheim, Canada Foundation for Innovation, Eshelman Institute for Innovation, Genome Canada, Innovative Medicines Initiative (EU/EFPIA [ULTRA-DD

grant no. 115766], Janssen, Merck \& Co., Novartis Pharma AG, Ontario Ministry of Economic Development and Innovation, Pfizer, São Paulo Research Foundation-FAPESP, Takeda, and Wellcome Trust [092809/Z/10/Z].

\section{AUTHOR INFORMATION}


aMedicine Design, Pfizer, 610 Main Street, Cambridge MA, 02139, USA. E-mail:

aldin.denny@pfizer.com; piatnits@gmail.com.

${ }^{\mathrm{b}}$ Medicine Design, Pfizer, Eastern Point Road, Groton CT, 06340, USA

'Structural Biology and Biophysics, Medicine Design, Pfizer, Eastern Point Road, Groton CT, 06340,

USA

${ }^{d}$ Primary Pharmacology Group, Pfizer, Eastern Point Road, Groton CT, 06340, USA

${ }^{e}$ Current address: Evotec (UK) Ltd, 114 Innovation Drive, Milton Park, Abingdon, Oxfordshire OX14 4RZ, UK.

fStructural Genomics Consortium, Target Discovery Institute, ARUK Oxford Drug Discovery Institute, University of Oxford, NDM Research Building, Roosevelt Drive, Oxford, OX3 7FZ, UK

${ }^{\mathrm{g}}$ Rare Disease Research Unit, Pfizer, 610 Main Street, Cambridge MA, 02139, USA

*Corresponding authors

RAD, ACF, JC, JL, AB, SL, IS, PS, PB, MP, LHJ and ELPC were employees and shareholders of Pfizer when the research was performed. 


\section{References}

1. Hewings, D. S.; Rooney, T. P.; Jennings, L. E.; Hay, D. A.; Schofield, C. J.; Brennan, P. E.; Knapp, S.; Conway, S. J., Progress in the development and application of small molecule inhibitors of bromodomain-acetyl-lysine interactions. J Med Chem 2012, 55 (22), 9393-413.

2. Prinjha, R. K.; Witherington, J.; Lee, K., Place your BETs: the therapeutic potential of bromodomains. Trends Pharmacol Sci 2012, 33 (3), 146-53.

3. (a) Floyd, S. R.; Pacold, M. E.; Huang, Q.; Clarke, S. M.; Lam, F. C.; Cannell, I. G.; Bryson, B. D.; Rameseder, J.; Lee, M. J.; Blake, E. J.; Fydrych, A.; Ho, R.; Greenberger, B. A.; Chen, G. C.; Maffa, A.; Del Rosario, A. M.; Root, D. E.; Carpenter, A. E.; Hahn, W. C.; Sabatini, D. M.; Chen, C. C.; White, F. M.; Bradner, J. E.; Yaffe, M. B., The bromodomain protein Brd4 insulates chromatin from DNA damage signalling. Nature 2013, 498 (7453), 246-50; (b) Taylor, A. M.; Cote, A.; Hewitt, M. C.; Pastor, R.; Leblanc, Y.; Nasveschuk, C. G.; Romero, F. A.; Crawford, T. D.; Cantone, N.; Jayaram, H.; Setser, J.; Murray, J.; Beresini, M. H.; de Leon Boenig, G.; Chen, Z.; Conery, A. R.; Cummings, R. T.; Dakin, L. A.; Flynn, E. M.; Huang, O. W.; Kaufman, S.; Keller, P. J.; Kiefer, J. R.; Lai, T.; Li, Y.; Liao, J.; Liu, W.; Lu, H.; Pardo, E.; Tsui, V.; Wang, J.; Wang, Y.; Xu, Z.; Yan, F.; Yu, D.; Zawadzke, L.; Zhu, X.; Zhu, X.; Sims, R. J., 3rd; Cochran, A. G.; Bellon, S.; Audia, J. E.; Magnuson, S.; Albrecht, B. K., Fragment-Based Discovery of a Selective and Cell-Active Benzodiazepinone CBP/EP300 Bromodomain Inhibitor (CPI-637). ACS Med Chem Lett 2016, 7 (5), 531-6; (c) Crawford, T. D.; Romero, F. A.; Lai, K. W.; Tsui, V.; Taylor, A. M.; de Leon Boenig, G.; Noland, C. L.; Murray, J.; Ly, J.; Choo, E. F.; Hunsaker, T. L.; Chan, E. W.; Merchant, M.; Kharbanda, S.; Gascoigne, K. E.; Kaufman, S.; Beresini, M. H.; Liao, J.; Liu, W.; Chen, K. X.; Chen, Z.; Conery, A. R.; Cote, A.; Jayaram, H.; Jiang, Y.; Kiefer, J. R.; Kleinheinz, T.; Li, Y.; Maher, J.; Pardo, E.; Poy, F.; Spillane, K. L.; Wang, F.; Wang, J.; Wei, X.; Xu, Z.; Xu, Z.; Yen, I.; Zawadzke, L.; Zhu, X.; Bellon, S.; Cummings, R.; Cochran, A. G.; Albrecht, B. K.; Magnuson, S., Discovery of a Potent and Selective in Vivo Probe (GNE-272) for the Bromodomains of CBP/EP300. J Med Chem 2016, 59 (23), 10549-10563.

4. $\quad$ Bunnage, M. E.; Chekler, E. L.; Jones, L. H., Target validation using chemical probes. Nat Chem Biol 2013, 9 (4), 195-9.

5. $\quad$ Chekler, E. L.; Pellegrino, J. A.; Lanz, T. A.; Denny, R. A.; Flick, A. C.; Coe, J.; Langille, J.; Basak, A.; Liu, S.; Stock, I. A.; Sahasrabudhe, P.; Bonin, P. D.; Lee, K.; Pletcher, M. T.; Jones, L. H., Transcriptional Profiling of a Selective CREB Binding Protein Bromodomain Inhibitor Highlights Therapeutic Opportunities. Chem Biol 2015, 22 (12), 1588-96.

6. (a) Hett, E. C.; Piatnitski Chekler, E. L.; Basak, A.; Bonin, P. D.; Denny, R. A.; Flick, A. C.; Geoghegan, K. F.; Liu, S.; Pletcher, M. T.; Sahasrabudhe, P.; Salter, S. C.; Stock, I. A.; Taylor, A. P.; Jones, L. H., Direct photocapture of bromodomains using tropolone chemical probes. MedChemComm 2015, 6 (6), 1018-1023; (b) Rooney, T. P.; Filippakopoulos, P.; Fedorov, O.; Picaud, S.; Cortopassi, W. A.; Hay, D. A.; Martin, S.; Tumber, A.; Rogers, C. M.; Philpott, M.; Wang, M.; Thompson, A. L.; Heightman, T. D.; Pryde, D. C.; Cook, A.; Paton, R. S.; Muller, S.; Knapp, S.; Brennan, P. E.; Conway, S. J., A series of potent CREBBP bromodomain ligands reveals an induced-fit pocket stabilized by a cation-pi interaction. Angew Chem Int Ed Engl 2014, 53 (24), 6126-30; (c) Hay, D. A.; Fedorov, O.; Martin, S.; Singleton, D. C.; Tallant, C.; Wells, C.; Picaud, S.; Philpott, M.; Monteiro, O. P.; Rogers, C. M.; Conway, S. J.; Rooney, T. P.; Tumber, A.; Yapp, C.; Filippakopoulos, P.; Bunnage, M. E.; Muller, S.; Knapp, S.; Schofield, C. J.; Brennan, P. E., Discovery and optimization of smallmolecule ligands for the CBP/p300 bromodomains. J Am Chem Soc 2014, 136 (26), 9308-19; (d) Hammitzsch, A.; Tallant, C.; Fedorov, O.; O'Mahony, A.; Brennan, P. E.; Hay, D. A.; Martinez, F. O.; Al-Mossawi, M. H.; de Wit, J.; Vecellio, M.; Wells, C.; Wordsworth, P.; Muller, S.; Knapp, S.; Bowness, P., CBP30, a selective CBP/p300 bromodomain inhibitor, suppresses human Th17 responses. Proc Natl Acad Sci U S A 2015, 112 (34), 10768-73. 
7. http://www.thesgc.org/chemical-probes/CBP30.

8. $\quad$ Hewings, D. S.; Wang, M.; Philpott, M.; Fedorov, O.; Uttarkar, S.; Filippakopoulos, P.; Picaud, S.; Vuppusetty, C.; Marsden, B.; Knapp, S.; Conway, S. J.; Heightman, T. D., 3,5-dimethylisoxazoles act as acetyl-lysine-mimetic bromodomain ligands. J Med Chem 2011, 54 (19), 6761-70.

9. $\quad$ Arrowsmith, C. H.; Bountra, C.; Fish, P. V.; Lee, K.; Schapira, M., Epigenetic protein families: a new frontier for drug discovery. Nat Rev Drug Discov 2012, 11 (5), 384-400.

10. Filippakopoulos, P.; Picaud, S.; Mangos, M.; Keates, T.; Lambert, J. P.; Barsyte-Lovejoy, D.; Felletar, I.; Volkmer, R.; Muller, S.; Pawson, T.; Gingras, A. C.; Arrowsmith, C. H.; Knapp, S., Histone recognition and large-scale structural analysis of the human bromodomain family. Cell 2012, 149 (1), 214-31.

11. Molecular Operating Environment (MOE), 2012; Chemical Computing Group Inc., 1010 Sherbooke St. West, Suite \#910, Montreal, QC, Canada, H3A 2R7, 2016.

12. (a) Dougherty, D. A.; Stauffer, D. A., Acetylcholine binding by a synthetic receptor: implications for biological recognition. Science 1990, 250 (4987), 1558-60; (b) Dougherty, D. A., Cation-pi interactions in chemistry and biology: a new view of benzene, Phe, Tyr, and Trp. Science 1996, 271 (5246), 163-8; (c) Gallivan, J. P.; Dougherty, D. A., Cation-pi interactions in structural biology. Proc Natl Acad Sci U S A 1999, 96 (17), 9459-64; (d) Dougherty, D. A., The cation-pi interaction. Acc Chem Res 2013, 46 (4), 885-93; (e) Xiu, X.; Puskar, N. L.; Shanata, J. A.; Lester, H. A.; Dougherty, D. A., Nicotine binding to brain receptors requires a strong cation-pi interaction. Nature 2009, 458 (7237), 534-7.

13. Hewings, D. S.; Fedorov, O.; Filippakopoulos, P.; Martin, S.; Picaud, S.; Tumber, A.; Wells, C.; Olcina, M. M.; Freeman, K.; Gill, A.; Ritchie, A. J.; Sheppard, D. W.; Russell, A. J.; Hammond, E. M.; Knapp, S.; Brennan, P. E.; Conway, S. J., Optimization of 3,5-dimethylisoxazole derivatives as potent bromodomain ligands. J Med Chem 2013, 56 (8), 3217-27.

14. (a) Edwards, M. P.; Price, D. A., Chapter 23 - Role of Physicochemical Properties and Ligand Lipophilicity Efficiency in Addressing Drug Safety Risks. In Annual Reports in Medicinal Chemistry, John, E. M., Ed. Academic Press: 2010; Vol. Volume 45, pp 380-391; (b) Leeson, P. D.; Springthorpe, B., The influence of drug-like concepts on decision-making in medicinal chemistry. Nat Rev Drug Discov 2007, 6 (11), 881-90.

15. http://www.discoverx.com/services/drug-discovery-development-services/epigeneticprofiling/bromoscan.

16. Xing, L.; Blakemore, D. C.; Narayanan, A.; Unwalla, R.; Lovering, F.; Denny, R. A.; Zhou, H.; Bunnage, M. E., Fluorine in drug design: a case study with fluoroanisoles. ChemMedChem 2015, 10 (4), 715-26.

17. (a) Bamborough, P.; Diallo, H.; Goodacre, J. D.; Gordon, L.; Lewis, A.; Seal, J. T.; Wilson, D. M.; Woodrow, M. D.; Chung, C. W., Fragment-based discovery of bromodomain inhibitors part 2: optimization of phenylisoxazole sulfonamides. J Med Chem 2012, 55 (2), 587-96; (b) Seal, J.; Lamotte, Y.; Donche, F.; Bouillot, A.; Mirguet, O.; Gellibert, F.; Nicodeme, E.; Krysa, G.; Kirilovsky, J.; Beinke, S.; McCleary, S.; Rioja, I.; Bamborough, P.; Chung, C. W.; Gordon, L.; Lewis, T.; Walker, A. L.; Cutler, L.; Lugo, D.; Wilson, D. M.; Witherington, J.; Lee, K.; Prinjha, R. K., Identification of a novel series of BET family bromodomain inhibitors: binding mode and profile of I-BET151 (GSK1210151A). Bioorg Med Chem Lett 2012, 22 (8), 2968-72; (c) Hay, D.; Fedorov, O.; Filippakopoulos, P.; Martin, S.; Philpott, M.; Picaud, S.; Hewings, D. S.; Uttakar, S.; Heightman, T. D.; Conway, S. J.; Knapp, S.; Brennan, P. E., The design and synthesis of 5- and 6isoxazolylbenzimidazoles as selective inhibitors of the BET bromodomains. Medchemcomm 2013, 4 (1), 140-144.

18. $\quad$ Schrödinger Release 2012: MacroModel, S., LLC, New York, NY, 2016.

19. http://www.petachem.com. 
$\underline{\text { Table of Content Graphics }}$

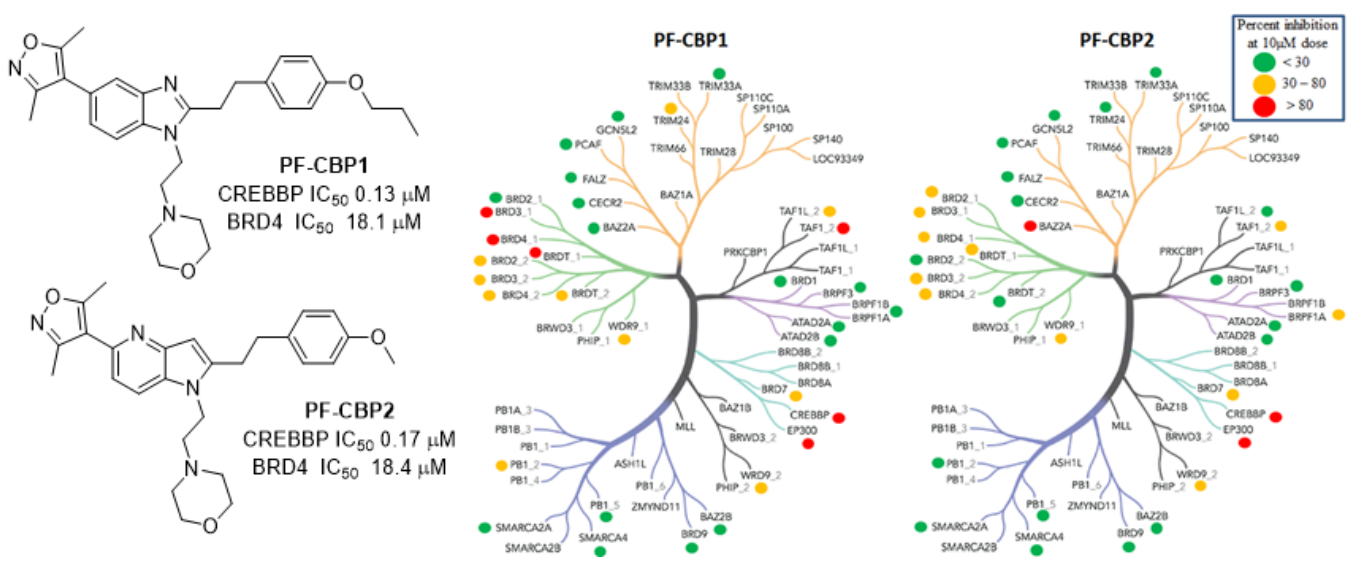

